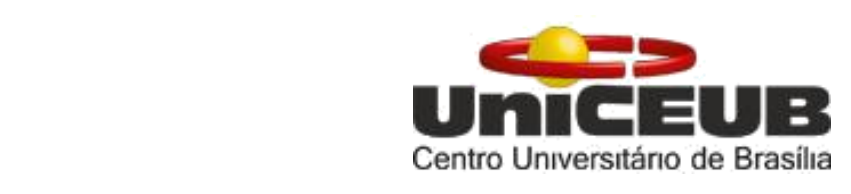

CENTRO UNIVERSITÁRIO DE BRASÍLIA - UniCEUB PROGRAMA DE INICIAÇÃo CIENTÍFICA

GABRIEL FONSECA DE BULHÕES IGOR NORAT CAVALCANTI

PROTEÔMICA DE BIOPSIAS LÍQUIDAS (SÉRICA E URINA) COMO BIOMARCADORES NOS ADENOCARCINOMAS COLORRETAIS

BRASÍLIA

2019 


\section{Unce $=\mathbf{B}$ \\ Centro Universitáno de Brașilia}

\section{GABRIEL FONSECA DE BULHÕES \\ IGOR NORAT CAVALCANTI}

\section{PROTEÔMICA DE BIOPSIAS LÍQUIDAS (SÉRICA E URINA) COMO BIOMARCADORES NOS ADENOCARCINOMAS COLORRETAIS}

Relatório final de pesquisa de Iniciação Científica apresentado à Assessoria de PósGraduação e Pesquisa.

Orientação: Profa. Dra. Aline Maria Araújo Martins.

\section{BRASÍLIA}

2019 
Gostaríamos de agradecer,

Primeiramente a Deus,

$e$ a todos os que, de alguma forma contribuíram para realização deste trabalho.

Em destaque aos colaboradores, Bruno Martins, Raphaela Menezes, Mickaella Martins e ao serviço de coloproctologia do HUB.

Um agradecimento especial aos pacientes que possibilitaram a realização do estudo.

Às nossas famílias e as pessoas próximas que sempre nos deram suporte para seguir nossos sonhos.

$E$, por último, um sincero agradecimento a pessoa que possibilitou um ano de novos aprendizados, experiências, oportunidades $e$ realizações, a nossa orientadora Aline Martins. 


\section{Sumário}

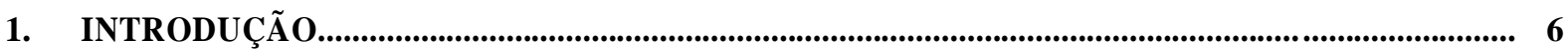

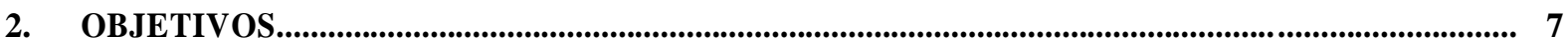

3. FUNDAMENTAÇÃO TEÓRICA: .......................................................................................... 7

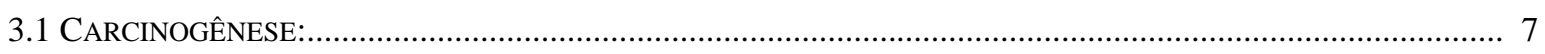

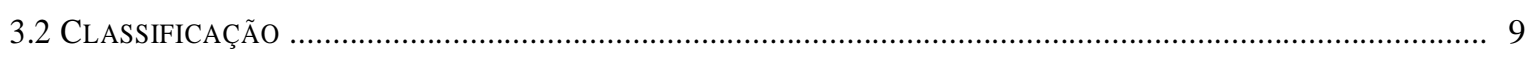

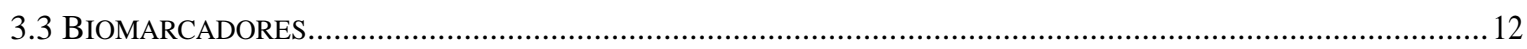

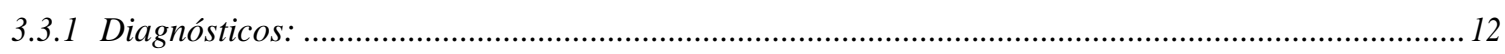

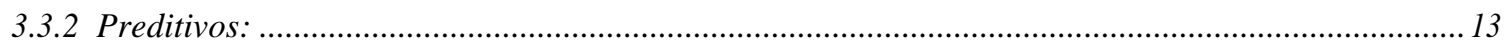

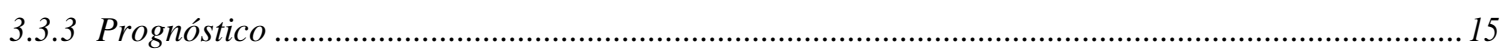

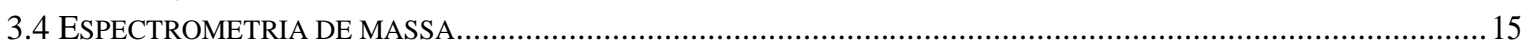

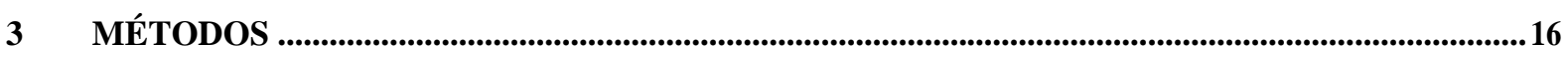

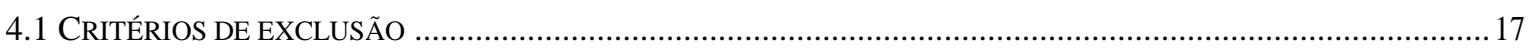

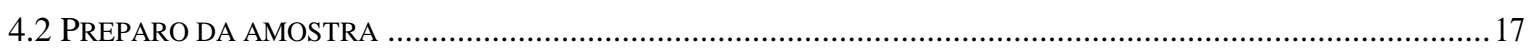

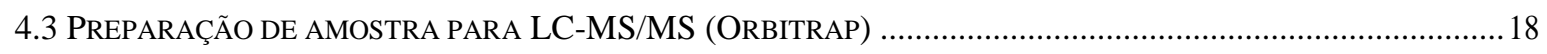

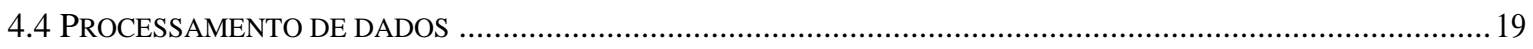

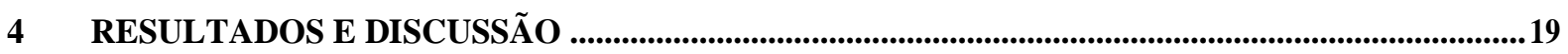

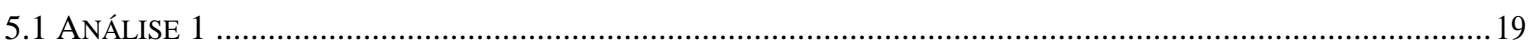

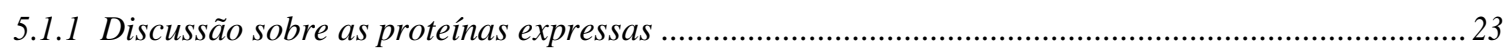

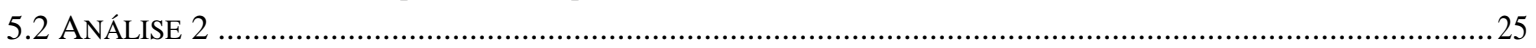

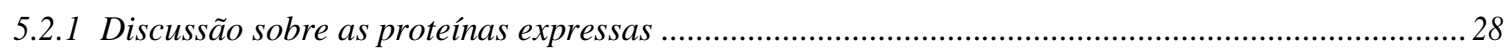

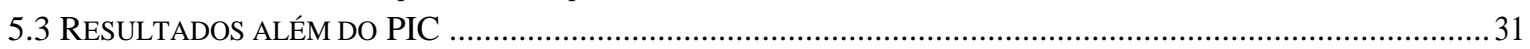

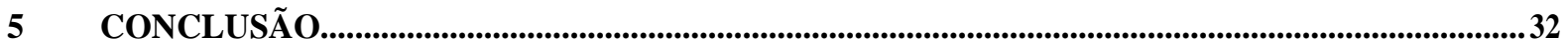

6 REFERÊNCIAS......................................................................................................................................... 


\title{
PROTEÔMICA DE BIOPSIAS LÍQUIDAS (SÉRICA E URINA) COMO BIOMARCADORES NOS ADENOCARCINOMAS COLORRETAIS
}

\author{
Resumo
}

\begin{abstract}
O câncer colorretal (CCR) é o terceiro mais prevalente no mundo, sendo que, cerca de $45 \%$ das vezes seu diagnóstico é tardio, geralmente apresentando metástase a distância tendo um prognóstico desfavorável. O padrão-ouro para o diagnóstico é a colonoscopia, no entanto esse exame apresenta diversos riscos como sangramento, perfuração, complicações cardiorrespiratórias e questões relacionadas ao pudor e desconforto, resultando em baixa adesão dos pacientes. Atualmente, o principal exame de rastreio do CCR é a pesquisa de sangue oculto nas fezes (SOF), porém esse possui baixa sensibilidade e especificidade. Sendo assim, se faz necessário a criação de novas ferramentas diagnósticas, como métodos menos invasivos usando biopsias líquidas. Neste trabalho foi realizado uma prospecção de proteínas presentes em biópsias líquidas (plasma e urina) por meio da espectrometria de massas entre um grupo de indivíduos portadores de neoplasia colorretal e de indivíduos não-patológicos (controle) visando definir possíveis biomarcadores. No estudo foram coletadas amostras de plasma e urina de 18 indivíduos, 9 pertencentes ao grupo CCR e 9 ao grupo controle, sendo extraídas as proteínas totais das amostras. Em seguida, essas foram submetidas a nanocromatografia usando uHPLC, os picos obtidos foram submetidos à análise do Orbitrap e Progenesis. Durante a análise foram separadas 18 proteínas com relevância estatística, sendo 5 delas provenientes do plasma e 13 da urina, podendo ser utilizadas como possíveis potenciais biomarcadores. Na literatura, algumas destas já foram descritas e relacionadas ao CCR, outras já foram associadas ao processo da carcinogênese, outras, ainda, não foram descritas no CCR ou no processo de carcinogênese. Assim, futuras pesquisas com focona validação dessas proteínas mais relevantes e avaliação de forma personalizada se faz necessário, além de alinhar a proteômica à outras técnicas, como a metabolômica.
\end{abstract}

Palavras-Chave: proteômica, câncer colorretal, espectrometria de massas. 


\section{Introdução}

O câncer colorretal (CCR) é o terceiro câncer mais comum em homens e o segundo mais comum em mulheres no Brasil e corresponde à quarta causa de mortalidade relacionada ao câncer no mundo (Figura 1) [1,2]. A maioria dos cânceres colorretais ocorre de maneira esporádica, sendo caracterizada por um processo de carcinogênese sequenciado que envolve o acúmulo progressivo de mutações em um período que dura em média 10 a 15 anos [3-7]. Esse longo intervalo de evolução permite a aplicação com sucesso do rastreamento, com detecção precoce do câncer e remoção das lesões pré-malignas, levando à redução na incidência e na mortalidade [69]. Contudo, mesmo com os mecanismos de diagnóstico precoce, cerca de $45 \%$ dos casos são diagnosticados no estadio IV, isso é, quando já ocorreu a metástase a distância, sendo que a sobrevida desses pacientes é menor que $10 \%$ em 5 anos [10].

\begin{tabular}{|c|c|c|c|c|c|c|c|}
\hline \multirow[b]{2}{*}{ Lacalinagle Prandita } & \multirow[b]{2}{*}{ Cased } & \multirow[b]{2}{*}{3} & & & \multicolumn{3}{|c|}{ sero, exceto pele nấo melanoma* } \\
\hline & & & & & Lecalingeds Priminte & Canst & s. \\
\hline Prtsata & 68.220 & $3 t, 7 x$ & Homens. & Maheres & Manu fermisina & 54.700 & 253 \\
\hline Traquice, Bsonque e Pulato & 18.740 & $8,7 x$ & & & Colon t Rets & 18990 & $9.4 \times$ \\
\hline Color entos & 17300 & s.ts & & & Colo so Uare & 16300 & 8.15 \\
\hline tesemipo & 1350 & 65 & & & Tlaques atonqig o Ruinto & 12.590 & $4 x$ \\
\hline Candath Oral & 11200 & 5.24 & & & Gindis fivode & 006 & 4,05 \\
\hline Esthpo & 8.240 & $3,6 x$ & & & Estbenopo & 7750 & 3,85 \\
\hline Bexige & $6690^{\circ}$ & 3,18 & & & Corpo do tew & 6.600 & $3,3 \mathbf{k}$ \\
\hline Lathes & 6390 & 3.05 & & & Ovate & 6.150 & $2.9 \mathrm{k}$ \\
\hline Lncertias & 5040 & $2.5 x$ & & & Statrma Nervese Ceter & ssida & $2.7 \pi$ \\
\hline Satera Nervado Certel & 5810 & $2, \pi \mathrm{k}$ & & & Concenas & 4800 & 2,65 \\
\hline
\end{tabular}

Figura 1. Incidências de cânceres, por sexo, no Brasil (INCA- Estimativa 2018).

O padrão-ouro para o diagnóstico de CCR é a colonoscopia, que identifica, classifica e remove as lesões pólipo adenomatosas, reduzindo a mortalidade do CCR [11,12]. Atualmente recomenda-se fazer o exame da colonoscopia como rastreio a partir dos 45 anos em pacientes sem antecedentes prévios [13]. Porém, é um procedimento invasivo que pode levar a riscos ao paciente como sangramento, perfuração, complicações cardiorrespiratórias e questões relacionadas ao pudor, desconforto, preparo colônico e necessidade de sedação, além de ser caro, resultando em baixa adesão pelos pacientes [7,14,15].

O método não invasivo mais utilizado para o rastreio do CCR, é a pesquisa de sangue oculto nas fezes (SOF), sendo o mais aceito pelos pacientes por ser um exame simples e de baixo custo, porém, este apresenta relativa baixa sensibilidade e especificidade, resultando em um alto número de testes falso-positivos e falso-negativos [5,6,16-18]. Outro marcador de 
grande importância é o antígeno carcinoembrionário (CEA), em que seus níveis elevados podem indicar progressão e recorrência da doença após o tratamento cirúrgico, sendo assim tendo um valor prognóstico. Além disso, os níveis de CEA não são específicos para o CCR, estando presentes em outra neoplasias e condições inflamatórias [19].

Pela atual abrangência de novas terapias para o CCR, como o aumento no número de quimioterápicos, abordagens neoadjuvantes e a recente aplicação de imunoterapia nos pacientes com CCR, é necessário também uma busca por novos biomarcadores preditivos para guiar o tratamento desses pacientes [20,21].

Diante disso, a pesquisa translacional proteômica se mostra de grande importância, uma vez que os tecidos neoplásicos e displásicos regulam a expressão de proteínas que vão traçar um perfil específico, este pode demonstrar uma progressão da patologia. Sendo assim, a expressão de um perfil proteico pode posteriormente ser aplicada na prática clínica [22,23].

\section{Objetivos}

Como objetivo para esta pesquisa foi traçado uma prospecção de proteínas em biópsias líquidas (plasma e urina) entre indivíduos portadores de neoplasia colorretal e indivíduos não-patológicos para a identificação de possíveis novos biomarcadores.

\section{Fundamentação Teórica:}

\subsection{Carcinogênese:}

O CCR é caracterizado por um processo de carcinogênese em que há mutações progressivas em uma média de tempo de 10-15 anos, além disso é um câncer em que na sua maioria ocorre de forma esporádica [3-6]. Esse processo de carcinogênese pode se dá pela ação de três pilares, a instabilidade cromossômica (CIN), metilação de ilhas GcP (CIMP) e instabilidade de microssatélites (MSI), esses pilares são complementares na progressão adenomacarcinoma da doença [24]. Em relação ao CIN, que se relaciona principalmente a apresentação esporádica $(85 \%)$, tem seus principais eventos envolvidos, a aneuploidia e a perda 
da sua heterozigose, ademais, esse processo ainda se correlaciona com a mutação do KRAS [25]. Já a via do CIMP age promovendo a hipermetilação de genes supressores de tumor, como os genes supressores o MGMT e o MLH1, e se relaciona por vezes a mutação do BRAF e a MSI. Por sua vez a via da MSI envolve a inativação de alterações genéticas em sequências curtas e repetidas. Essa ativação ocorre em genes de reparo de incompatibilidade (MMR) de DNA, sendo uma condição marcante na síndrome de Lynch familiar, também aparecendo em aproximadamente 15\% dos casos esporádicos de CCR [26]. Além disso, a hipermetilação dos genes MMR pode levar à MSI. Os tumores do MSI são frequentemente associados ao cólon proximal e ao baixo nível de diferenciação, porém possuem melhor prognóstico [27].

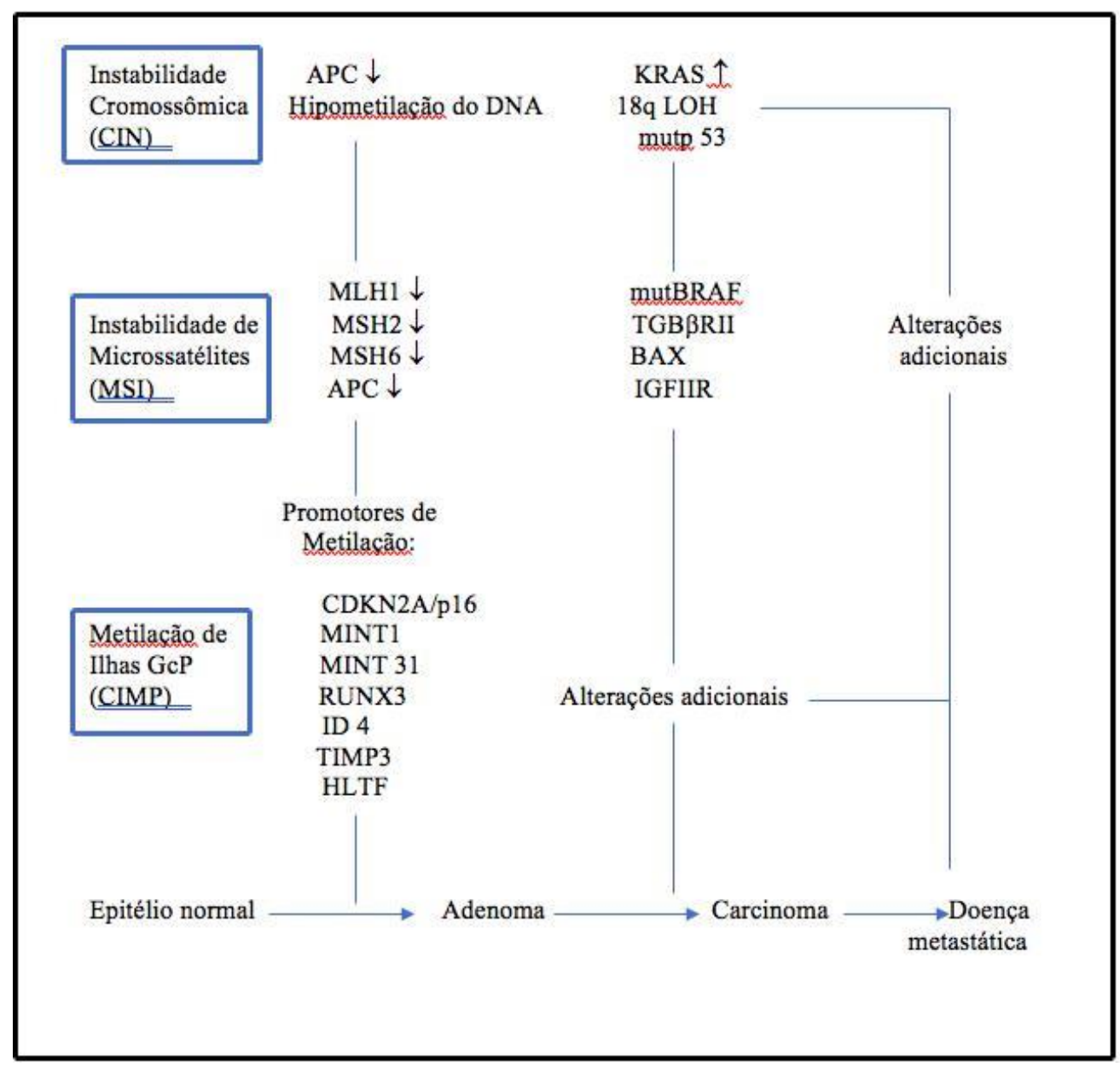

Figura 2: Desenho esquemático da carcinogêneses do câncer colorretal. Adaptado de: Cancer Biol Med. 2016 Mar; 13(1): 120-135. doi: 10.28092/j.issn.2095-3941.2015.0103 


\subsection{Classificação}

De acordo com a $8^{\mathrm{a}}$ edição da AJCC [28] (The American Joint Committee on Cancer), o estadiamento do CCR é feito por meio da classificação TNM, somado a evidências clínicas moleculares, como a presença de MSI, mutações do BRAF como fator prognóstico e mutações presentes no BRAF, KRAS e NRAS como fatores preditivos. A classificação TNM ainda é feita por meio da clínica (cTNM), com exames como Tomografia computadorizada (TC), Ressonância Magnética (RNM), e PET-SCAN, e do histopatológico (pTNM) por meio da ressecção da peça cirúrgica. A classificação patológica se dá pela avaliação do:

\section{. (T) Tumor primário:}

TX: Tumor primário não pode ser acessado.

T0: Não há evidência de tumor primário

Tis: Carcinoma in situ: intra epitelial ou invade a lâmina própria

T1: Tumor invade a submucosa

T2: Tumor invade a camada muscular própria

T3: Tumor atravessa a muscular própria atingindo tecidos pericólicos.

T4: Tumor invade o peritônio visceral ou tecidos adjacentes.

- T4a: Tumor invade o peritônio visceral.

- T4b:Tumor invade diretamente áreas ou se a adere a órgãos e estruturas adjacentes. 

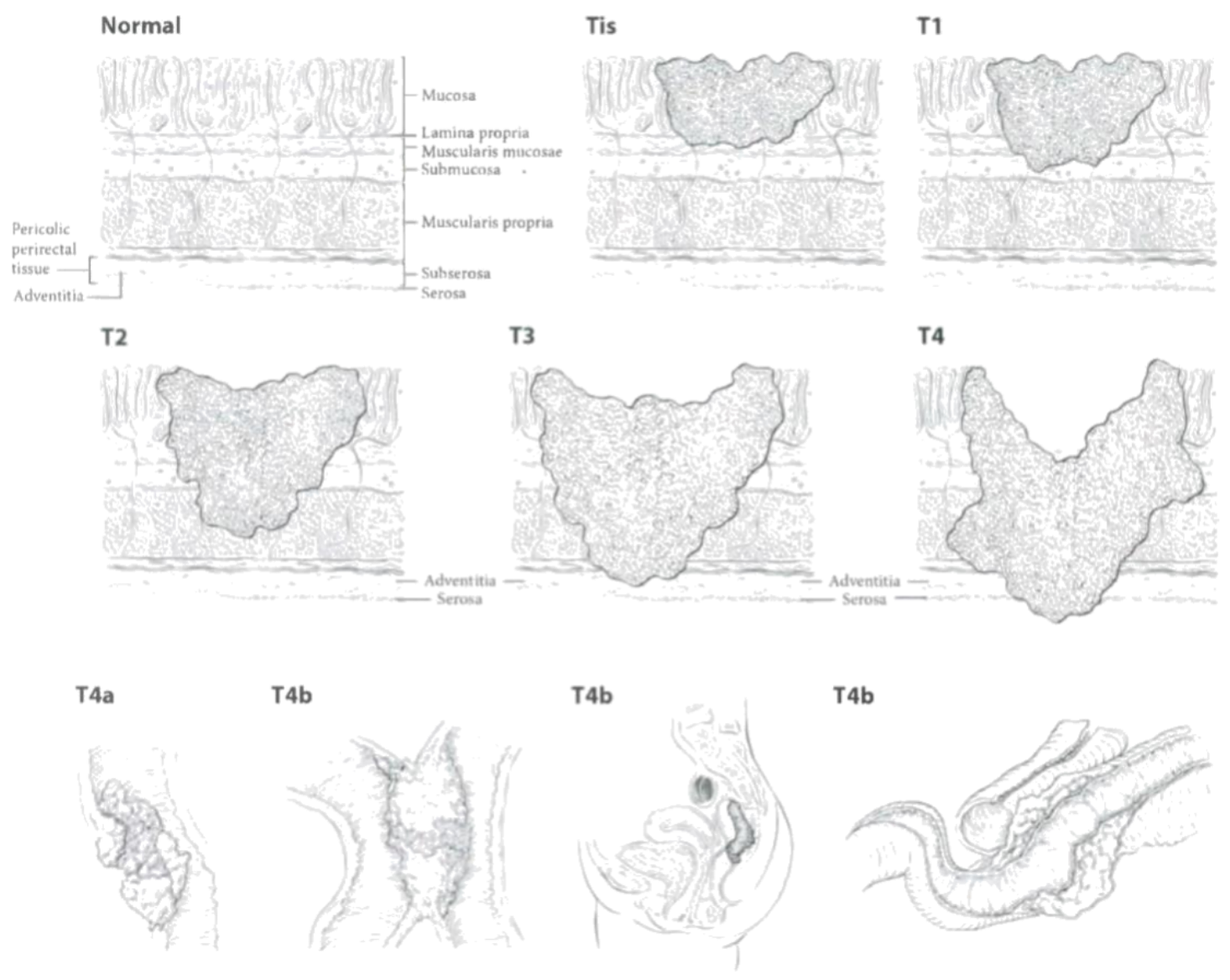

Figura 3: Imagem esquemática representando o estadiamento tumoral do câncer colorretal. Fonte: Weiser MR. AJCC 8th Edition: Colorectal Cancer. Ann. Surg. Oncol. [Internet]. 2018 Jun 3 [cited 2019 May 17];25(6):1454-1455. Available from: http://link.springer.com/10.1245/s10434-018-6462-1. Página 257.

\section{. (N) Linfonodos:}

NX: Linfonodos regionais não podem ser avaliados.

N0: Ausência metástase de linfonodos

N1: 1-3 linfonodos regionais são positivos

- N1a: Metástase em 1 linfonodo regional.

- N1b: Metástase em 2-3 linfonodos regionais.

- N1c: Depósito tumoral na subserosa mesentérica ou em tecidos pericólicos ou perirretais não peritonizados sem a presença de metástases linfonodais.

N2: 4 ou mais linfonodos regionais positivos.

- N2a: 4-6 linfonodos regionais positivos.

- $\quad$ N2b: 7 ou mais linfonodos positivos. 


\section{- (M) Metástase:}

M0: Ausência de metástase a distância

M1: É identificado 1 ou mais sítios de metástase em órgãos ou no peritônio

- M1a: 1 sítio de metástase confinada ou a distância em órgãos, sem a invasão peritoneal.

- M1b: 2 ou mais sítios de metástase e confinados ou a distância em órgãos, sem invasão peritoneal.

- M1c: A metástase é encontrada na face peritoneal sozinha ou associada a outro sítio ou órgão.

De acordo com a classificação TNM, se define o estadiamento do indivíduo:

Tabela 1: Tabela representando o estadiamento do câncer colorretal. Adaptado de: Weiser MR. AJCC 8th Edition: Colorectal Cancer. Ann. Surg. Oncol. [Internet]. 2018 Jun 3 [cited 2019 May 17];25(6):1454-1455. Available from: http://link.springer.com/10.1245/s10434018-6462-1

\begin{tabular}{|l|l|l|l|}
\hline Tumor & N (linfonodo) & M (metástase) & Estadio \\
\hline Tis & N0 & M0 & 0 \\
\hline T1,T2 & N0 & M0 & 1 \\
\hline T3 & N0 & M0 & II A \\
\hline T4a & N0 & M0 & II B \\
\hline T4b & N0 & M0 & II C \\
\hline T1-T2 & N1/N1c & M0 & III A \\
\hline T1 & N2a & M0 & III A \\
\hline T3-T4a & N1/N1c & M0 & III B \\
\hline T2-T3 & N2a & M0 & III B \\
\hline T1-T2 & N2b & M0 & III B \\
\hline T4a & N2a & M0 & III C \\
\hline
\end{tabular}




\begin{tabular}{|l|l|l|l|}
\hline T3-T4a & N2b & M0 & III C \\
\hline T4b & N1-N2 & M0 & III C \\
\hline Qualquer T & Qualquer N & M1a & IV A \\
\hline Qualquer T & Qualquer N & M1b & IV B \\
\hline Qualquer T & Qualquer N & M1c & IV C \\
\hline
\end{tabular}

\subsection{Biomarcadores}

A detecção de biomarcadores são de suma importância tendo em vista que esses possuem diversas aplicabilidades que variam entre, detecção precoce da doença, estratificação de prognóstico, vigilância e determinação de tratamento personalizado [29-31]. O biomarcador de maior utilização no CCR é o antígeno carcinoembrionário (CEA), encontrado em tecidos embrionários e neoplasias colorretais é uma glicoproteína de alto peso molecular que foi descrita, primeiramente, em 1965 e é utilizada como marcador prognóstico até hoje, vale ressaltar que não é uma proteína exclusiva do CCR [19]. E que hoje não é o único marcador de prognóstico, pois se tem marcadores genéticos como MSI e mutação do gene BRAF [32]. Um outro exemplo, seriam os biomarcadores preditivos, que se mostraram de grande importância na decisão do tratamento de pacientes com drogas antagonistas do receptor de fator de crescimento epidérmico (EGFR), em pacientes com mutações no KRAS [23].

Tendo em vista a importância de biomarcadores, há recentes atualizações em genômica, transcriptômica, proteômica e metabolômica, que estão aumentando a possibilidade de candidatos à biomarcadores [14-16,33-36]. Diante disso, foi levantado uma revisão dos mais recentes biomarcadores encontrados na literatura, e seus valores diagnósticos, preditivos e prognósticos.

\subsubsection{Diagnósticos:}


Os estudos recentes realizaram diversas análises para encontrar novos candidatos a marcadores diagnósticos, procurando principalmente no tecido e no plasma dos indivíduos estudados.

Ghazanfar e colaboradores (2017), compararam amostras de tecidos sadios e CCR em 12 pacientes, demonstrando uma maior expressão da proteína similar a actina beta-2 (ACTBL2) no tecido tumoral [37]. Hao e colaboradores (2017), avaliaram 22 pares de tecidos de indivíduos com CCR, analisando seu tecido normal e neoplásico, evidenciando uma maior expressão de dipeptidase-1 (DPEP1) [38]. Quesada-Calvo e col (2017), analisaram 76 amostras de tecidos CCR em estágios iniciais (pT1N0M0 e pT2N0M0), normais ou com a mucosa inflamada, mostrando diferentes níveis de olfactomedina-4 (OLFM4), kininogenio-1 (KNG1) e proteína transportadora Sec24 (Sec24C) nos tecidos CCR em estágios iniciais quando comparadas ao tecido normal e pré-maligno [32]. Yamamoto e col (2016), mostraram uma maior expressão da ciclofilina A, anexina A2 e aldolase A em tecido neoplásicos quando comparados com o tecido normal [39].

Os marcadores sanguíneos são de grande importância no diagnóstico precoce e no rastreio do CCR, pois suas amostras podem ser facilmente obtidas com baixo custo e risco ao paciente $[33,40]$.

Fan e col (2016), conduziu um estudo com amostras séricas mostrando uma maior regulação do receptor de manose 1 do macrofágo (MRC1) e proteína ligante de cácio S100 A9 (S100A9) em pacientes com CCR [41]. Os membros da família SERPINA também foram descritos como potenciais biomarcadores séricos para pólipos adenomatosos e carcinomas colorretais, como a SERPINA 1 (alfa-1 antitripsina), SERPINA 3 (alfa-1 antiquimotripsina) e as SERPINC1 (Antitrombina-3) [42].

Yu e col (2017), realizaram uma pesquisa com 127 amostras séricas de pacientes com CCR e 90 de pacientes sem CCR, nisso se verificou uma menor expressão da proteína serina/treonina cinase 4 (STK4 ou MST1) em pacientes com CCR. Essa proteína sozinha, não demonstrou uma grande sensibilidade ou especificidade, porém quando combinadas ao CEA e o SOF, teve uma sensibilidade de $92,3 \%$ e especificidade de $100 \%$ no diagnóstico de CCR. Sendo assim, é perceptível que apenas uma proteína apenas não será suficiente para definir um novo biomarcador absoluto, mas quando alia-se à outros biomarcadores pode-se obter uma melhora na sensibilidade e especificidade, tendo como exemplo o estudo do MST1 [43].

\subsubsection{Preditivos:}


Os biomarcadores preditivos são principalmente utilizados para definir a resposta a um tratamento e para guiar a terapia escolhida em cada paciente. Sendo a proteômica de grande importância para a interpretação dessas análises. Wang e col (2017), em seu estudo, fez uma abordagem utilizando proteômica, genômica e transcriptômica, para análise de sensibilidade a drogas utilizadas no tratamento do CCR, mostrando que o estudo proteômico possuia um melhor potencial para a análise da sensibilidade ao tratamento com uso de 5-fluoracil, SN-38, erlotinib, regofenib e oxiplatina quando comparadas a genômica e transcriptômica [44].

Guo e col (2017), investigou proteínas que poderiam estar relacionadas a resistência ao tratamento com oxiplatina, ele fez uma comparação do proteoma de células sensíveis a oxiplatina HT-29 e de celulas resistentes a oxiplatina HT-29, mostrando uma maior expressão da poliproteína ( C ) de ligação 1 (PCBP1) em tecidos de tumores resistentes a oxiplatina, sugerindo que ela seja um marcador de resistência no CCR em culturas de células [45].

Martin e col (2014) avaliou a resposta ao tratamento com inibidor do crescimento vascular endotelial (bevacizumad), em pacientes com doença metastática, fazendo uma análise de 23 amostras séricas de pacientes que ainda iam fazer o tratamento. O estudo revelou 3 proteínas, apoliproteína E (APOE), angiotensinogênio (AGT) e a proteína de ligação a vitamina D (DBP) e associadas a melhor sobrevida em indivíduos tratados com a quimioterapia junto ao bevacizumab [46].

Pacientes com cancer retal, quanso esse está localizado (estagio II e III), se faz quimioradioterapia neoadjuvante seguido de cirurgia [47]. A quimioradioterapia neoadjuvante ocorre para controle local do tumor, porém cerca de 10-20\% dos pacientes possuem uma resposta patológica completa a terapia. Dessa maneira, poderia selecionar pacientes para a cirurgia, como proposto por Habr-Gama e col (2014) [48]. Todavia, uma das maiores dificuldades é determinar se o paciente teve resposta patológica completa a quimioradioterapia neoadjuvante. Chauvin e col (2018) destacou um perfil proteico estudando biópsias de tecidos tumorais, identificando uma maior expressão de Proteína induzida por interferon com repetições de tetratricopeptídeo 1(IFIT1), Domínios FAST Kinase 2 (FASTKD2), fosfatidilinositol-5 fosfato 4-quinase tipo 2 beta (PIP4K2B), domínio interativo rico em AT contendo proteína 1B (ARID1B) e família transportadora de soluto 25 membro 33 (SLC25A33), no tecido tumoral de pacientes com resposta patológica completa [49].

O estudo de um linfonodo acometido também é de grande importância para a definir a terapia do paciente com CCR, ele resulta em um pior prognóstico diminuindo a sobrevida do paciente [50]. Sendo que sua investigação por meio de exames de imagem como TC, RNM e USG, possui baixa acurácia [51]. Diante disso, metodos nao invasivos podem indicar 
quimioterapia ou uma maior ressecção da peça cirúrgica. Mori e col (2017), mostrou uma maior expressão da proteína heatshock 47 (HSP47) tecidos tumorais de pacientes com metastase linfonodal [52].

\subsubsection{Prognóstico}

Um Biomarcador prognóstico informa o desfecho final do câncer do paciente, independente da terapia utilizada [53]. O prognóstico do CCR é bastante variável, podendo ser diferente em paciente em um mesmo estadio, essas variações ocorrem devido ao processo complexo da carcinogênese, envolvendo diversos mecanismos genéticos, vias de sinalização e eventos epigenéticos [32].

O principal fator de pior prognostico no CCR é a metástase, sendo seu principal sítio metastático o fígado, diminuindo a sobrevida em 5 anos para cerca de $8 \%$ em pacientes no estadio IV [54,55]. Zhu e col (2013), comparou amostras séricas de pacientes com metástase metacrômica hepática com indivíduos sem recidiva da metástase ou com pelo menos 3 anos após cirurgia, identificando as proteínas alfa-fetoproteína, complemento C4-A, fibrinogênio alfa, fator de liberação da cadeia peptídica eucariótica subunidade de ligação ao GTP ERF3B e angiotensinogênio no plasma de pacientes com metástase metacrômica hepática [56].

As proteínas do colágeno parecem ser promissores biomarcadores para a metástase no CCR. Um estudo comparou o tecido da metástase hepática com um tecido normal adjacente a ele, em pacientes com CCR, mostrando um aumento da expressão de colágeno tipo XII na metástase hepática [57]. Alguns estudos ainda demonstram a capacidade de encontrar essas proteínas do colágeno na urina com metástase hepática [58,59]. Para a análise da recorrência do CCR, ainda foram levantados alguns biomarcadores prognósticos por Clarke e col (2017), o estudo demonstrou 8 proteínas relacionadas a recorrência do tumor, colágeno IV, forkheadbox O3, inositol polifosfato-4 fosfatase, tirosina cinase LcK, fosfo-PEA15 (Ser116), fosfo-PRAS40, Rad51 e fosfo-S6 (Ser240-244) [60].

\subsection{Espectrometria de massas}


A maioria dos estudos feitos em busca de novos biomarcadores são baseados em técnicas quantitativas em espectrometria de massa (MS) para identificação e validação de proteínas candidatas a novos biomarcadores [33]. A MS é uma ferramenta que avalia espécies ionizadas em uma fase gasosa aferindo sua razão massa-carga $(\mathrm{m} / \mathrm{z})$. Esta ferramenta consiste em uma fonte de íons- que é responsável por converter a molécula estudada em uma espécie ionizada- , um analisador de massa- este separará os íons conforme sua m/z-, e um detectorque irá perceber esta separação dos íons e os armazenará em dados eletrônicos- [61,62].

Deve-se ressaltar que a MS é um método extremamente sensível e aplicável em pequenas amostras, gerando dados relevantes e até projetando interações entre proteínas. Desse modo, é a ferramenta mais utilizada quando estudada análise proteômica translacional [63].

\section{Métodos}

Inicialmente foram avaliados 29 indivíduos estes sendo divididos em pacientes portadores de CCR e pacientes sadios (grupo controle), sendo 15 do grupo de pacientes com CCR e 14 do grupo controle, porém após avaliarmos com os critérios de exclusão foram resultantes 9 indivíduos pertencentes ao grupo controle e 9 ao grupo CCR.

Sendo assim, foram avaliados plasmas e amostras de urina de 18 pacientes, coletados no momento do exame de colonoscopia: $I$ ) nove pacientes submetidos a colonoscopia que apresentam carcinomas na região do cólon e II) nove pacientes submetidos a colonoscopia que não apresentam carcinomas na região do cólon (controle). As características clínicopatológicas estão representadas na Tabela 2.O material biológico foi proveniente do Serviço de Coloproctologia do Hospital Universitário de Brasília (HUB). Dados referentes ao quadro clínico, história familiar, antecedentes patológicos e hábitos de vida também foram coletados (CAAE 83200917.9.0000.5558).

Tabela 2. Característica clínico-patológicas

\begin{tabular}{|l|r|r|}
\hline & Grupo CCR $(\mathrm{n}=9)$ & Grupo Controle $(\mathrm{n}=9)$ \\
\hline Sexo & $3(33,3 \%)$ & $3(33,3 \%)$ \\
Masculino & $6(66,7 \%)$ & $6(66,7 \%)$ \\
Feminino & & \\
\hline
\end{tabular}




\begin{tabular}{|c|c|c|}
\hline $\begin{array}{l}\text { Idade (anos, mediana } \\
\text { [variação]) }\end{array}$ & $62[43-85]$ & $63[38-76]$ \\
\hline IMC $\left(\mathrm{kg} / \mathrm{m}^{2}, \quad\right.$ mediana & $23,7[17,5-30,1]$ & $27,04[22,9-335,9]$ \\
[variação]) & $1(11,1 \%)$ & - \\
\hline Estadiamento & $3(33,3 \%)$ & - \\
I & $3(33,3 \%)$ & - \\
II & $2(22,2 \%)$ & - \\
III & $3(33,3 \%)$ & - \\
IV & $2(22,2 \%)$ & - \\
Cólon direito & $4(44,4 \%)$ & - \\
Cólon esquerdo & $2,78[1,17-180]$ & \\
Reto & & \\
\hline CEA (mediana $[\mathrm{ng} / \mathrm{ml}] /$ & & \\
variação) & & \\
\hline
\end{tabular}

\subsection{Critérios de exclusão}

- Portadores de doença inflamatória intestinal;

- Portadores de polipose adenomatose familiar;

- Portadores de câncer colorretal hereditário não polipose;

- Portadores de demais síndromes de câncer colorretal hereditárias;

- Pacientes que realizaram quimioterapia e/ou radioterapia neoadjuvante;

- Pacientes com tumores sincrônicos.

\subsection{Preparo da amostra}

As amostras contendo $5 \mathrm{ml}$ de sangue periférico foram coletadas por acesso central no momento do exame colonoscópico, não sendo adicionadas nenhuma rotina nova, já que é 
necessário o acesso para administração do fármaco fentanil e midazolan (procedimento padrão no momento do exame). Foi feito o processo de depleção na amostra sanguínea, para a retirada de proteínas abundantes no sangue como imunoglobulinas e a albumina.

Dois mililitros de plasma foram então obtidos por centrifugação (5000 x g/ 6 min.) gerados e lisados em $8 \mathrm{M}$ ureia contendo coquetel completo de inibidores de proteases (Roche) e de fosfatases (Roche). O extrato proteico foi precipitado com acetona $100 \%$ a 4oC, ressuspendido em tampão $100 \mathrm{mM}$ bicarbonato de amônio (ABC) em 8M ureia, reduzido com 20 mM DTT por uma hora, alquilado com 40 mM IAA por no mínimo uma hora no escuro para serem digeridos. No dia seguinte a solução foi diluída quatro vezes com $100 \mathrm{mM}$ ABC, quantificada para proteínas totais (método Qbit@, ThermoFisher) e foi adicionado tripsina modificada (Promega) na proporção 1:50 e incubados por mais 3 horas. Em seguida as amostras foram acidificadas com concentração final de TFA igual a 0,1\% (v:v) e foram dessalinizadas em microcolunas home made de resina de fase reversa C18. A urina foi coletada imediatamente antes ao exame a fim de evitar falsas identificações por metabolização de fármaco administrado no exame. Cinco mililitros de urina foram então processados, com o uso do mesmo método do plasma.

\subsection{Preparação de amostra para LC-MS/MS (Orbitrap)}

As amostras foram analisadas por um sistema UHPLC-nano (Dionex) acoplado online com um espectrômetro de massas LTQ-Orbitrap Elite (ThermoScientific). $\mathrm{Na} 1^{\text {a }}$ fase do processamento analítico foi realizada cromatografia com $6 \mu \mathrm{g}$ de proteína total extraída a partir do volume inicial de amostra foram carregados em uma coluna PepSwift Monolithic Trap Column de $5 \mathrm{~cm}$ (diâmetro interno de $200 \mu \mathrm{m}$, Dionex-nanoViper), as proteínas totais fracionadas em uma coluna analítica de alta resolução PepSwift Monolithic Nano Column de $25 \mathrm{~cm}$ (diâmetro interno de $100 \mu \mathrm{m}$, Dionex-nanoViper) e eluídas usando um gradiente de $100 \%$ fase A $(0.1 \%$ ác. fórmico) até $26 \%$ fase B ( $0.1 \%$ ác. fórmico, $95 \%$ acetonitrila) por $180 \mathrm{~min}, 26 \%$ até $100 \%$ fase B por $5 \mathrm{~min}$ e $100 \%$ fase B por $8 \mathrm{~min}$ (um total de $193 \mathrm{~min}$ a $200 \mathrm{~nL} / \mathrm{min}$ ). Após cada corrida, a coluna foi lavada com $90 \%$ fase B e reequilibrada com fase A. Os espectros de massas foram adquiridos no modo positivo aplicando-se Data-Dependent Automatic Survey MS Scan e aquisição de espectros de massas em tandem (MS/MS). Cada MS no Orbitrap (amplitude de massa: m/z 350-1800 e resolução: 120000) foi seguida por MS/MS 
dos quinze íons mais intensos no LTQ. A fragmentação no LTQ ocorreu por dissociação de alta energia induzida por colisão (HCD) e as sequências de íons selecionados foram excluídas dinamicamente por 15 segundos.

\subsection{Processamento de dados}

Os softwares Peaks e Progenesis (ThermoScientific) foram usados para analisar e interpretar dados relativos à comparação das amostras biológicas propostas para a busca de possíveis marcadores de prognóstico negativo (proteínas reguladas positivamente no CCR) ou de possíveis marcadores de prognóstico positivo (proteínas reguladas positivamente no controle) que foram submetidos à colonoscopia.

\section{Resultados e Discussão}

No presente estudo os resultados são avaliados por meio da determinação de dois padrões de análises comparativas:

1- Comparação dos perfis expressos no plasma do grupo controle e do grupo de indivíduos com CCR.

2- Comparação dos perfis expressos na urina do grupo controle e do grupo de indivíduos com CCR.

Para a determinação da relevância dos dados, foi usado o valor do fold-change, este se baseia em uma análise apenas numérica de quantas vezes a amostra se encontra (no caso do presente estudo a proteína) mais em um cenário que em outro [64]. Nos resultados foi considerado como relevantes amostras que possuíram o FOLD maior ou igual 5.

\subsection{Análise 1}


Nesta análise foram comparadas amostras de plasma entre pacientes pertencentes ao grupo controle e ao grupo de indivíduos com CCR.

Foram identificadas 36 proteínas, sendo que dessas apenas quatro se demonstraram relevantes $(F O L D \geq 5)$ : Variante da subunidade beta da hemoglobina, Isoforma CRA $\mathrm{n}$ da fibronectina 1, Cadeia da globina alfa-2 mutante e Ceruloplasmina. Apesar de não possuir um FOLD $\geq 5$, a Transferrina merece ser ressaltada uma vez que apresenta valor de $p$ de 0,08 .

Tabela 3. Proteínas reguladas nas amostras de plasma.

\begin{tabular}{|c|c|c|c|c|c|}
\hline UniPROT & FOLD & $\begin{array}{l}\text { Valor de } \\
\text { p }\end{array}$ & Proteína & \multicolumn{2}{|c|}{$\begin{array}{l}\text { CTRL } \quad \text { x CCR } \\
\text { Grupo de maior expressão }\end{array}$} \\
\hline Q06AH7 & 1,35 & 0,08 & Transferrina & $\mathrm{X}$ & \\
\hline Q9UK54 & $5,21^{*}$ & 0,02 & $\begin{array}{l}\text { Variante da } \\
\text { subunidade beta da } \\
\text { hemoglobina }\end{array}$ & $\mathrm{X}$ & \\
\hline V9HWA & 1,16 & 0,32 & $\begin{array}{l}\text { Proteína ligante } 62 \mathrm{p} \\
\text { secretora do } \\
\text { espermatozoide do } \\
\text { epidídimo }\end{array}$ & $\mathrm{X}$ & \\
\hline P02671 & 1,16 & 0,28 & $\begin{array}{l}\text { Cadeia alfa do } \\
\text { fibrinogênio }\end{array}$ & $\mathrm{X}$ & \\
\hline $\mathrm{P} 02671$ & 1,46 & 0,32 & $\begin{array}{l}\text { Proteína altamente } \\
\text { similiar à cadeia } \mathrm{C} \text { da } \\
\text { imunoglobina alfa- } 1\end{array}$ & $\mathrm{X}$ & \\
\hline A0A140VJJ6 & 1,19 & 0,30 & $\begin{array}{l}\text { Proteína Li } 70 \text { do } \\
\text { tecido testicular }\end{array}$ & $\bar{X}$ & \\
\hline $\mathrm{P} 01023$ & 1,50 & 0,09 & $\begin{array}{l}\text { Alfa-2- } \\
\text { macroglobulina }\end{array}$ & $\mathrm{X}$ & \\
\hline D3DP13 & 1,12 & 0,27 & $\begin{array}{l}\text { Isoforma CRA_e da } \\
\text { cadeia beta do } \\
\text { fibrinogênio }\end{array}$ & $\mathrm{X}$ & \\
\hline A0A0C4DGL8 & 1,20 & 0,63 & Haptoglobina & & $\mathrm{X}$ \\
\hline P02647 & 1,27 & 0,33 & Apoliproteína A-I & $\mathrm{X}$ & \\
\hline A0A140TA32 & 1,23 & 0,27 & Complemento C4-A & & $\mathrm{X}$ \\
\hline A0A0G2JRN3 & 1,11 & 0,83 & Alfa-1-antitripsina & & $\bar{X}$ \\
\hline E1A689 & 1,24 & 0,68 & $\begin{array}{l}\text { Apolipoproteína B } \\
\text { mutante }\end{array}$ & & $\mathrm{X}$ \\
\hline P02790 & 1,17 & 0,18 & Hemopexina & $\mathrm{X}$ & \\
\hline Q68DH2 & 1,04 & 0,50 & $\begin{array}{l}\text { Proteína não } \\
\text { caracterizada } \\
\text { DKFZp686G21125 } \\
\end{array}$ & $\mathrm{X}$ & \\
\hline
\end{tabular}




\begin{tabular}{|c|c|c|c|c|c|}
\hline P0DOX6 & 1,47 & 0,15 & $\begin{array}{l}\text { Cadeia pesada de } \\
\text { imunoglobulina } 1\end{array}$ & $\mathrm{X}$ & \\
\hline A0A096LPE2 & 1,10 & 0,64 & $\begin{array}{l}\text { Proteína SAA2-SAA4 } \\
\text { readthrough }\end{array}$ & & $\mathrm{X}$ \\
\hline Q7Z3Y4 & 1,15 & 0,32 & $\begin{array}{l}\text { Proteína não } \\
\text { caracterizada }\end{array}$ & $\mathrm{X}$ & \\
\hline V9HWD8 & 1,27 & 0,12 & $\begin{array}{l}\text { Proteína ligante } \\
\text { 163pA secretora do } \\
\text { esperma do epidídimo }\end{array}$ & $\mathrm{X}$ & \\
\hline A0A024R962 & 1,18 & 0,30 & $\begin{array}{l}\text { Isoforma CRA_b da } \\
\text { proteína HCG40889 }\end{array}$ & $\bar{X}$ & \\
\hline D6RF35 & 1,21 & 0,21 & $\begin{array}{l}\text { Proteína ligante da } \\
\text { vitamina D }\end{array}$ & $\mathrm{X}$ & \\
\hline Q5T985 & 1,19 & 0,45 & $\begin{array}{l}\text { Cadeia pesada } \mathrm{H} 2 \text { do } \\
\text { inibidor da inter-alfa- } \\
\text { tripsina }\end{array}$ & & $\mathrm{X}$ \\
\hline P05090 & 1,01 & 0,51 & Apolipoproteína D & & $\bar{X}$ \\
\hline S6B2B0 & 1,38 & 0,99 & Cadeia L da IgG & & $\bar{X}$ \\
\hline G3V3A0 & 1,22 & 0,87 & $\begin{array}{l}\text { Alfa-1- } \\
\text { antiquimotripsina }\end{array}$ & & $\mathrm{X}$ \\
\hline A0A1U9X7H7 & 1,70 & 0,15 & Fator complemento B & $\bar{X}$ & \\
\hline F8WAS2 & 1,03 & 0,42 & $\begin{array}{l}\text { Cadeia pesada } \mathrm{H} 1 \text { do } \\
\text { inibidor da inter-alfa- } \\
\text { tripsina }\end{array}$ & $\mathrm{X}$ & \\
\hline $\mathrm{A} 0 \mathrm{~A} 024 \mathrm{R} 462$ & $15,47 *$ & 0,09 & $\begin{array}{l}\text { Isoforma CRA_n da } \\
\text { fibronectina-1 }\end{array}$ & $\mathrm{X}$ & \\
\hline B4DPP8 & 1,39 & 0,36 & $\begin{array}{l}\text { Proteína altamente } \\
\text { similiar ao } \\
\text { quininogênio-1 }\end{array}$ & $\mathrm{X}$ & \\
\hline K7ERI9 & 1,63 & 0,23 & $\begin{array}{l}\text { Fragmento da } \\
\text { apoliproteína C-I }\end{array}$ & $\bar{X}$ & \\
\hline D1MGQ2 & $20,78^{*}$ & 0,23 & $\begin{array}{l}\text { Cadeia globina alfa- } 2 \\
\text { mutante }\end{array}$ & $\bar{X}$ & \\
\hline A5PL27 & $16,41 *$ & 0,19 & Ceruloplasmina & $\mathrm{X}$ & \\
\hline F8WCZ6 & 1,43 & 0,23 & $\begin{array}{l}\text { Subcomponente do } \\
\text { complemento C1s }\end{array}$ & & $\bar{X}$ \\
\hline B0ZBE2 & 1,34 & 0,61 & Angiotensinogênio & & $\mathrm{X}$ \\
\hline P00739 & 0,6 & 1,51 & $\begin{array}{l}\text { Proteína relacionada à } \\
\text { haptoglobina }\end{array}$ & & $\bar{X}$ \\
\hline P02787 & 0,48 & 1,15 & Serotransferrina & & $\mathrm{X}$ \\
\hline
\end{tabular}

De acordo com o perfil global das proteínas expressas no plasma dos grupos, o software Progenesis QI realizou a interpretação dos dados de perfis similares (PCA) que está demonstrada na Figura 4. 


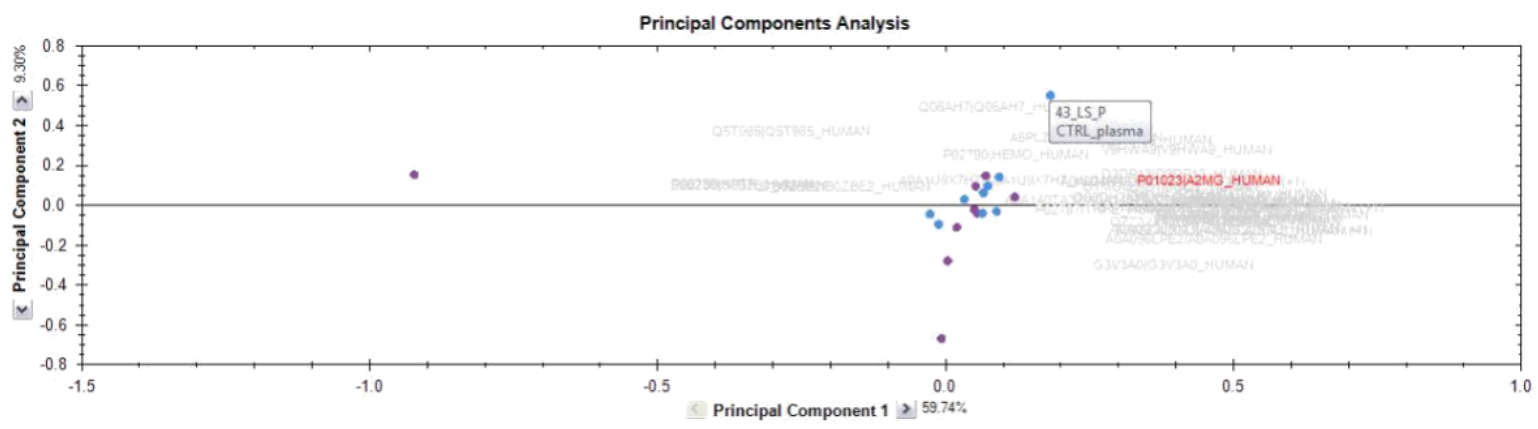

Figura 4. Apresenta a análise PCA, realizada pelo software Progenesis, das proteínas reguladas nas amostras plasmáticas entre os grupos CCR (cor roxa) e controle (cor azul).

As anotações do termo GO foram realizadas avaliando três componentes: Componentes celulares, processos biológicos e funções moleculares. A análise de componentes celulares registrou que as proteínas expressas foram localizadas principalmente no meio extracelular (39\%) (Figura 5). Em relação a análise de processos biológicos, as proteínas estão ligadas a regulação $(27 \%)$, processos celulares $(12 \%)$ e resposta à estímulos (12\%) (Figura 6). Por sua vez as funções moleculares as quais as proteínas mais se afiliaram foi de ligação (45\%) e atividade catalítica (13\%) (Figura7).

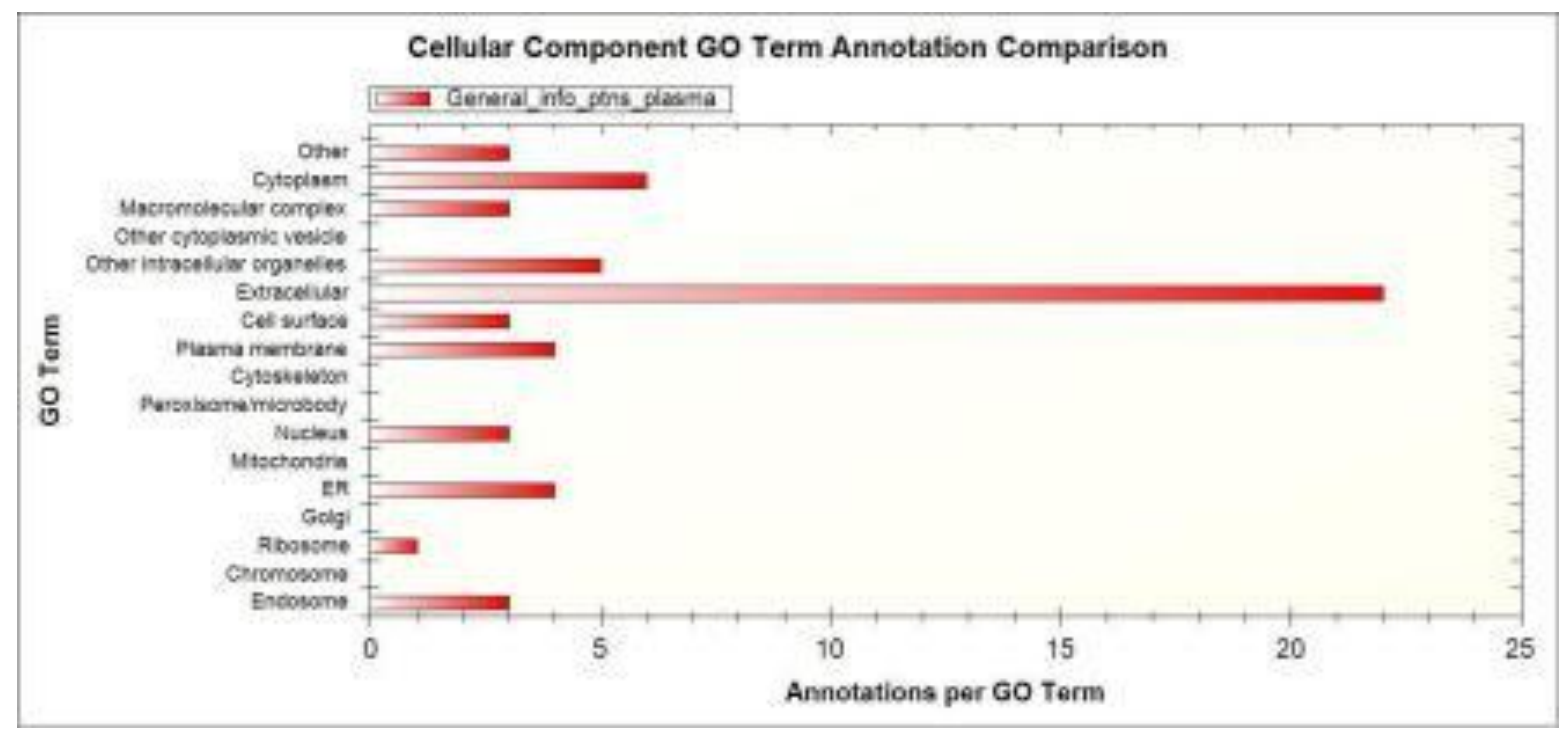

Figura 10. Anotações em termo GO quanto ao componente celular para proteínas reguladas no plasma 


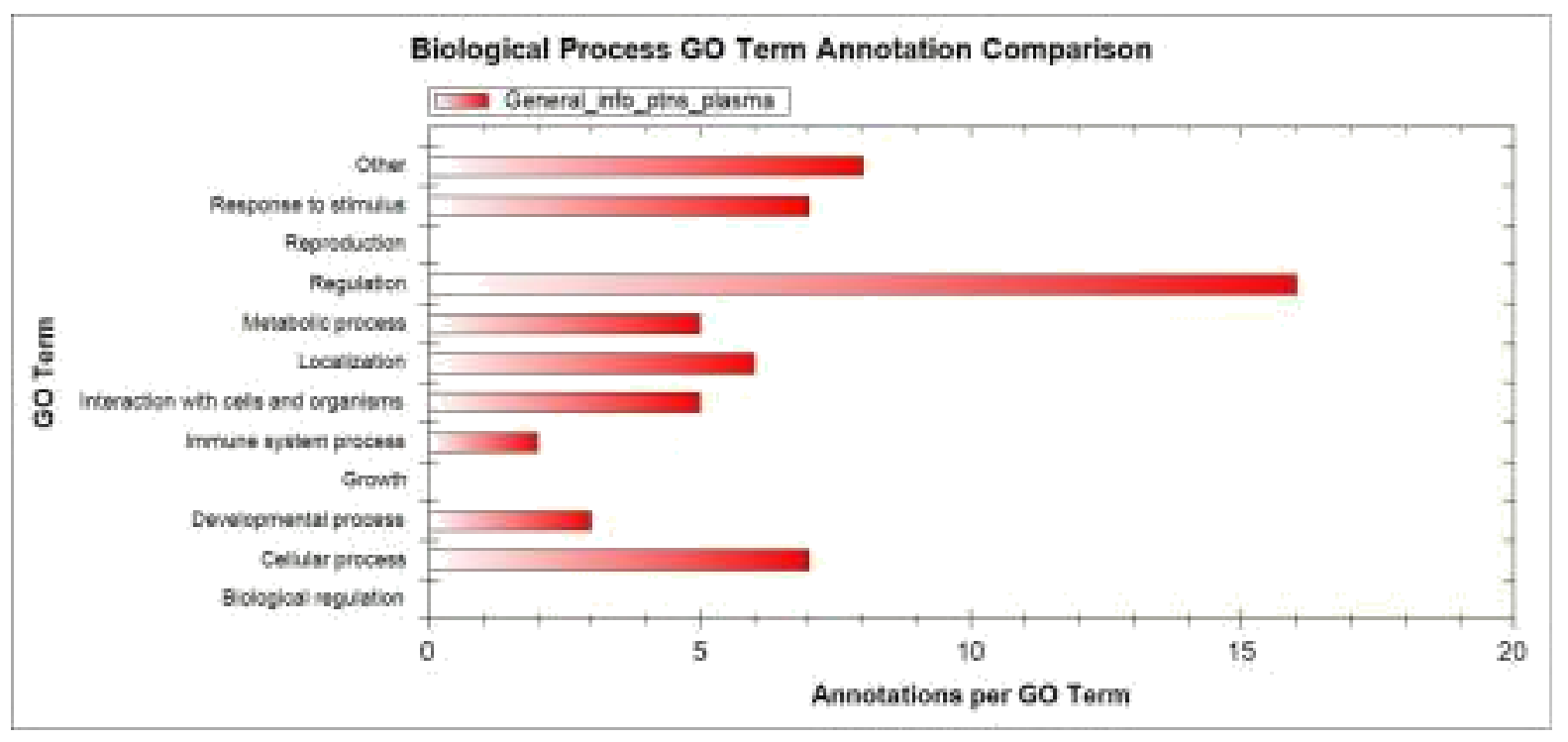

Figura 11. Anotações em termo GO quanto aos processos biológicos para proteínas reguladas no plasma

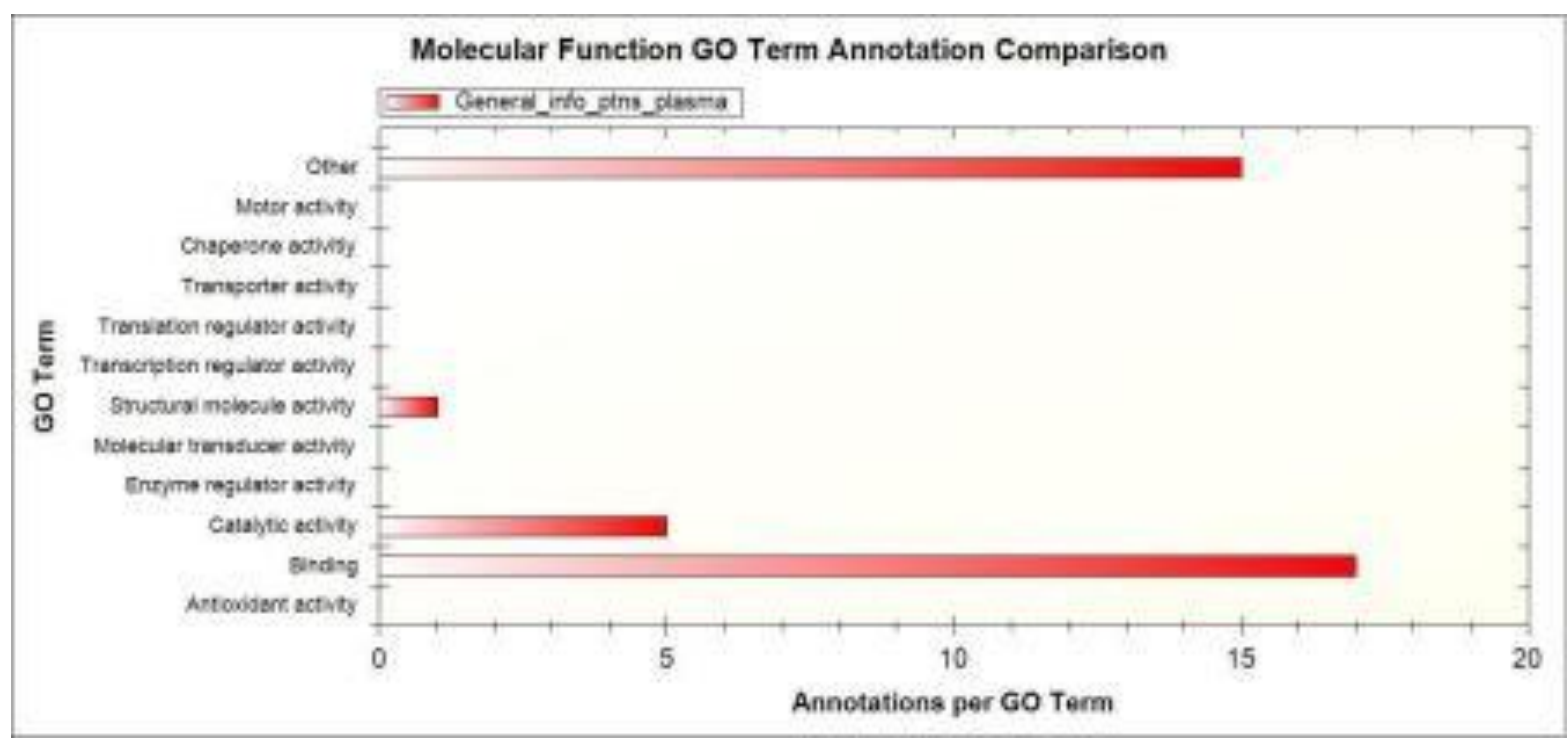

Figura 7. Anotação do termo $\mathrm{GO}$ em relação a função molecular sobre as proteínas expressas nas amostras plasmáticas.

\subsubsection{Discussão sobre as proteínas expressas}

Devido as amostras de sangue poderem ser facilmente obtidas, de forma pouco invasiva e com baixo custo, elas se mostram um dos principais potenciais para meio de análise, tendo utilidade no diagnóstico precoce, vigilância e acompanhamento do CCR [33,40]. Diante disso, foram selecionadas 5 proteínas com relevância, 4 com um FOLD $\geq 5$, e uma com $p=0,08$.

\section{- Variante da subunidade beta da hemoglobina}


Chol e col, (2013), em seu estudo, levantou possíveis proteínas relacionadas as progressão adenoma-carcinoma no CCR. Nos pacientes estudados, foi encontrado uma maior expressão da subunidade beta da hemoglobina [65]. Ademais, já se foi correlacionado que as subunidade alfa e beta da hemoglobina como prováveis biomarcadores no câncer de ovário [66].

\section{- Cadeia da globina alfa-2 mutante}

Pela a análise de tecidos tumorais e sadios, Rho e col (2008), encontram uma menor expressão da subunidade alfa da hemoglobina, em tecidos tumorais no CCR [67]. Além disso, um estudo feito com a matriz fecal de murinos identificou diversas proteínas com potencial diagnóstico no CCR, uma delas foi a subunidade alfa da hemoglobina [68].

\section{- Isoforma CRA n da fibronectina 1}

O tamanho e a forma de um tumor no CCR, está diretamente relacionado ao seu comportamento clinico e também serve como um marcador de malignidade [69,70]. As lesões iniciais no epitélio podem ser superficiais (pólipos e não poliposas), ou deprimidos (cerca de 2,3\%), tendo assim uma maior dificuldade de detecção [71,72]. Um estudo baseado na análise por DNA microarray, demonstrou que o gene da fibronectina 1 estava relativamente mais expresso em lesões do tipo depressivas [73].

Cai X e col (2018), demonstrou em seu estudo que a fibronectina 1 estava mais expressa em adenocarcinomas colorretais, indicando que essa proteína pode estar relacionada a carcinogênese do CCR [74].

\section{- Ceruloplasmina}

A ceruloplasmina é uma proteína sintetizada no fígado que possui inúmeras funções no organismo como, na oxidação do ferro e sua ligação a transferrina, transporte do cobre para os tecidos, remoção do ion superóxido e modulação da resposta inflamatória [75].

A proteína foi relacionada a outros tipos de canceres, como o adenocarnoma de pâncreas [76] no câncer de ovário [77], e no de vias biliares [78] Porém, nada na literatura atual mostrou alguma correlação com o CCR.

\section{- Transferrina}


O metabolismo do ferro parece estar intimamente correlacionado a diversas neoplasias epiteliais como o de mama, fígado e colorretal [79-81]. Sabe-se ainda que uma elevada saturação da transferrina ainda se relaciona ao desenvolvimento de cancer [82]. Estudo feito por Ward e col (2006), relevou 3 principais proteínas relacionadas ao diagnóstico de CCR, transferrina, alfa-1-antitripsina e o complemento C3a [83].

\subsection{Análise 2}

Nesta análise foram comparadas amostras da urina entre pacientes pertencentes ao grupo controle e ao grupo de indivíduos com CCR.

Foram identificadas 13 proteínas, sendo que, dez dessas se demonstraram relevantes por possuir $\mathrm{FOLD} \geq 5$, estas foram: Fragmento da isoforma 1 do colágeno tipo 1 alfa-2, Apolipoproteína D, Fator Intrínseco- receptor de vitamina B12 (Fragmento), Pro-fator de crescimento epidermal, Cininogênio 1 , Altamente similar à proteína da matriz extracelular 1 semelhante a fibulina contendo EGF, Fragmento alfa- amilase, Fragmento da proteína 1 de interação com a fosfatidilinositol- 3-quinase, Domínios de homologia à plecstrina contendo membro 5 da família A e Fragmento da variante da cadeia pesada da imunoglobulina. Porém, houveram 3 proteínas que, apesar, de possuírem um $\mathrm{FOLD}<5$, possuem um valor de $\mathrm{P} \leq 0,05$, merecem serem destacadas, Essas são: Uromodulina, Fragmento de beta-2- microglobulina e Titina.

Tabela 4. Proteínas reguladas nas amostras de urina.

\begin{tabular}{|l|l|l|l|l|l|}
\hline UniPROT & FOLD & $\begin{array}{l}\text { Valor } \\
\text { de } \mathbf{p}\end{array}$ & Proteína & \multicolumn{2}{|l|}{$\begin{array}{l}\text { CTRL x CCR } \\
\text { expressão }\end{array}$} \\
\hline A0A0S2Z3H5 & 6,81 & 0,03 & $\begin{array}{l}\text { Fragmento da isoforma 1 do } \\
\text { colágeno tipo 1, alfa-2 }\end{array}$ & $\mathrm{X}$ & \\
\hline P05090 & 7,34 & 0,04 & Apolipoproteína D & $\mathrm{X}$ & \\
\hline P07911 & 4,34 & 0,03 & Uromodulina & $\mathrm{X}$ & \\
\hline Q7LC53 & 6,18 & 0,06 & Fator Intrínseco- receptor de & $\mathrm{X}$ & \\
& & & vitamina B12 (Fragmento) & & \\
\hline P01133 & 14,81 & 0,07 & Pro-fator de crescimento epidermal & $\mathrm{X}$ & \\
\hline
\end{tabular}




\begin{tabular}{|c|c|c|c|c|c|}
\hline Q05CF8 & 10,60 & 0,02 & Cininogênio 1 & $\mathrm{X}$ & \\
\hline H0YLF3 & 2,62 & 0,05 & $\begin{array}{l}\text { Fragmento de beta-2- } \\
\text { microglobulina }\end{array}$ & & $\mathrm{X}$ \\
\hline B4DWH0 & 10,71 & 0,05 & $\begin{array}{l}\text { Altamente similar à proteína da } \\
\text { matriz extracelular } 1 \text { semelhante a } \\
\text { fibulina contendo EGF }\end{array}$ & $\mathrm{X}$ & \\
\hline Q6NSB3 & 37,68 & $\begin{array}{l}7,47 \mathrm{e}- \\
003\end{array}$ & Fragmento alfa- amilase & $\mathrm{X}$ & \\
\hline C9JMK5 & 6,57 & 0,01 & $\begin{array}{l}\text { Fragmento da proteína } 1 \mathrm{de} \\
\text { interação com a fosfatidilinositol- } \\
\text { 3-quinase }\end{array}$ & $\mathrm{X}$ & \\
\hline C0JYZ2 & 2,71 & 0,05 & Titina & $\mathrm{X}$ & \\
\hline Q9HAU0 & 5,78 & 0,05 & $\begin{array}{l}\text { Domínios de homologia à } \\
\text { plecstrina contendo membro } 5 \text { da } \\
\text { família A }\end{array}$ & $\mathrm{X}$ & \\
\hline Q9NPP6 & 5,72 & 0,06 & $\begin{array}{l}\text { Fragmento da variante da cadeia } \\
\text { pesada da imunoglobulina }\end{array}$ & $\mathrm{X}$ & \\
\hline
\end{tabular}

De acordo com o perfil global das proteínas expressas na urina dos grupos, o software Progenesis QI realizou a interpretação dos dados de perfis similares (PCA) que está demonstrada na Figura 8.

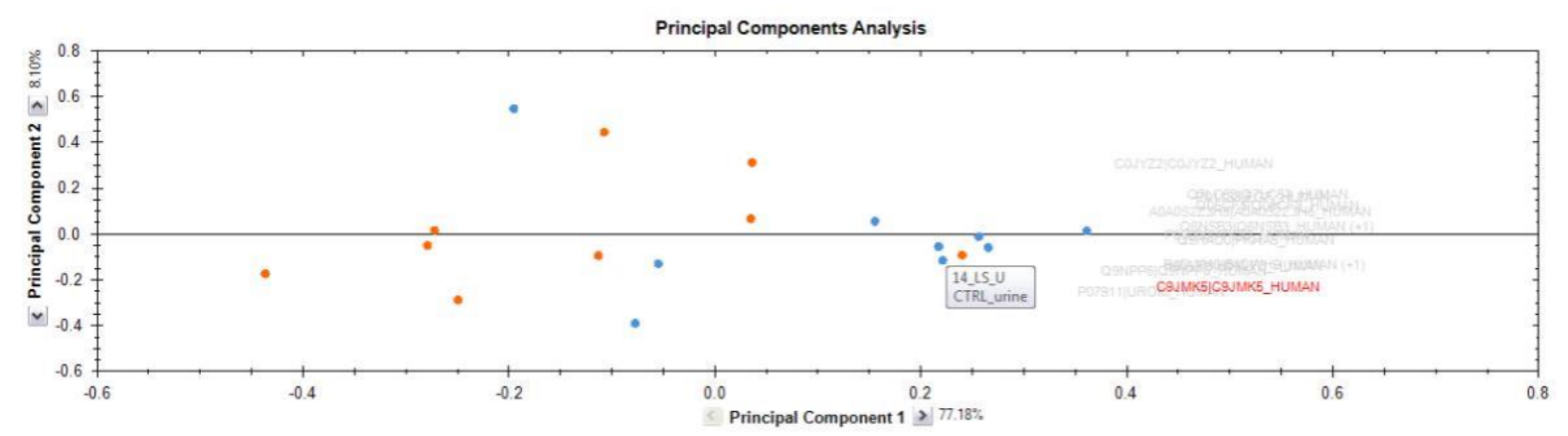

Figura 8. Apresenta a análise PCA, realizada pelo software Progenesis, das proteínas reguladas nas amostras de urina entre os grupos CCR (cor azul) e controle (cor laranja).

Foi realizada as anotações do termo GO em três componentes: Componentes celulares, processos biológicos e funções moleculares. Em relação aos componentes celulares foi evidenciado que as proteínas expressas se localizam majoritariamente em meio extracelular (23\%) e em membrana plasmática (14\%) (Figura 9). Já nos processos biológicos foi verificado que as proteínas estão ligadas ao desenvolvimento (23\%), processos celulares (14\%), processos 
metabólicos (14\%) e regulação (14\%) (Figura 10). Por sua vez as funções moleculares as quais as proteínas estão relacionadas são ligação (53\%) e atividade catalítica (24\%) (Figura 11).

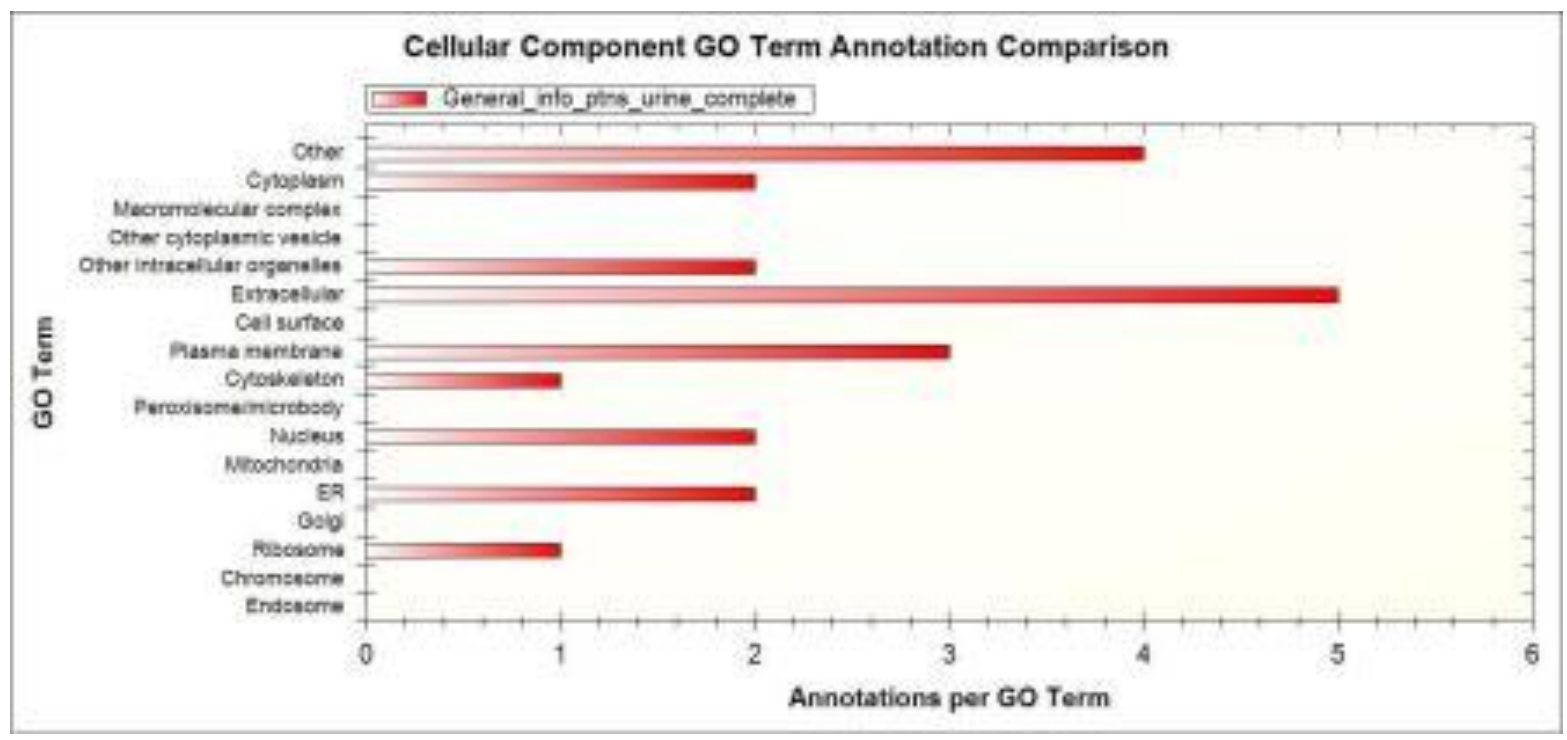

Figura 15. Anotações em termo GO quanto ao componente celular para proteínas reguladas na urina Figura 9. Anotação do termo GO em relação a componentes celulares sobre as proteínas expressas nas amostras urinárias.

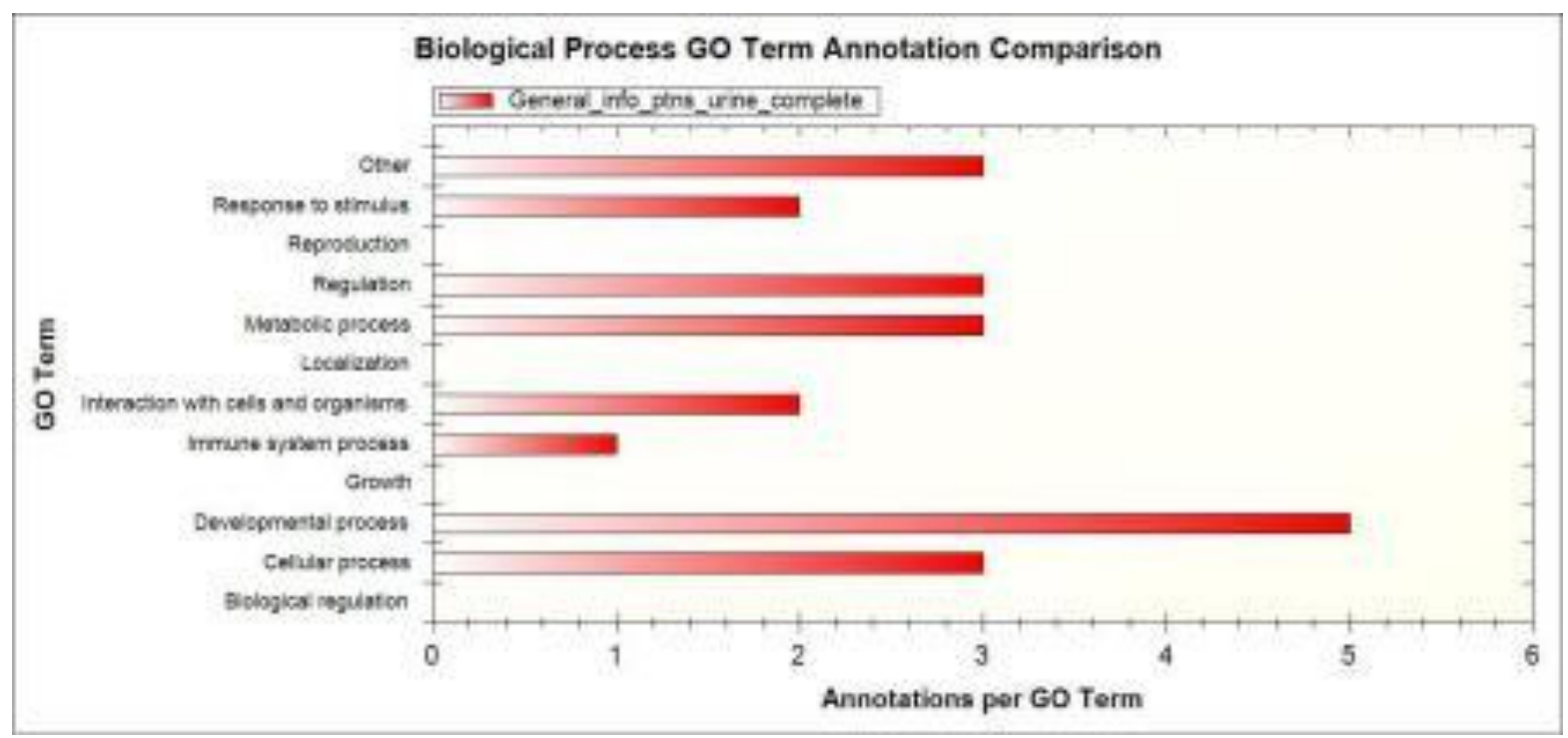

Figura 16. Anotações em termo GO quanto aos processos biológicos para proteínas reguladas na urina Figura 10. . Anotação do termo GO em relação a processos biológicos sobre as proteínas expressas nas amostras urinárias. 


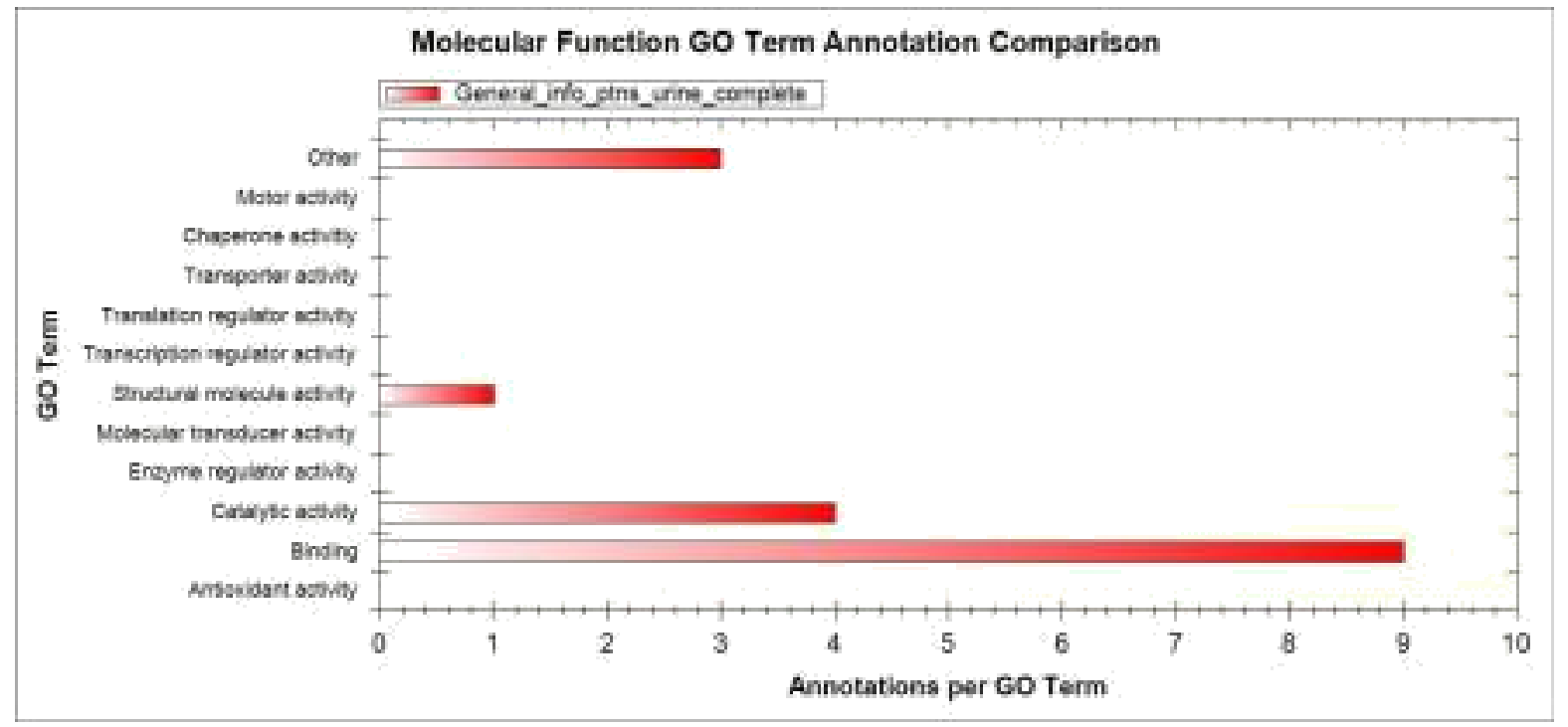

Figura 17. Anotações em termo GO quanto à função molecular para proteínas reguladas na urina Figura 11. . Anotação do termo GO em relação a funções moleculares sobre as proteínas expressas nas amostras urinárias.

\subsubsection{Discussão sobre as proteínas expressas}

É importante ressaltar as limitações de uma pesquisa de proteômica em amostras urinárias, uma vez que há a filtração renal, onde, além de outras substâncias, as proteínas não atravessam a filtração glomerular. Desse modo, em condições normais há pouca disponibilidade de proteínas na urina.

Apesar disso, a proteína se demonstra interessante para prospecção de amostras tendo em vista sua fácil obtenção [33]. Alguns dos exemplos da importância dessa biópsia líquida é a obtenção de potenciais biomarcadores como o PGE-M, que se encontra aumentado quando há progressão da neoplasia CCR, e como o peptídeos de colágeno que foram descritos como possíveis marcadores de metástases no CCR [84-88].

Dessa forma, serão debatidas as proteínas que possuem relevância estatística apresentando FOLD $\geq 5$, mencionando também as que apresentaram o valor de $p<0,05$.

\section{- Isoforma 1do colágeno tipo 1 alfa 2}

Essa proteína já foi correlacionada à neoplasias anteriormente, durante o processo de progressão da neoplasia o colágeno é remodelado pelas metaloproteinases, tendo assim algum nível de colágeno degradado na corrente sanguínea, podendo ser um potencial biomarcador 
[89](137-tese). O colágeno tipo 1 é o mais abundante dentre os da família do colágeno, sendo formado por duas cadeias, alfa-1 (COL1A1) e alfa-2 (COL1A2) [90,91].

A exata função desta proteína ainda não foi bem elucidada, porém apesar de grande parte dos estudos apontarem que proteínas colágeno estão hiper-regulada no CCR, podendo ser apontada por alguns como preditora de metástases hepática, o COL1A2 aparenta apresentar regulação negativa no CCR devido a hipermetilação do seu gene codificador. Um estudo realizado in vitro constatou que o COL1A2 inibe a progressão da neoplasia [57,90-92].

Neste estudo, a proteína em questão foi encontrada regulada negativamente no grupo CCR quando comparado ao grupo controle.

\section{- Apolipoproteína D}

É uma proteína que aparenta estar relacionada com o ciclo e a proliferação celular, e seu acúmulo já foi evidenciado em doenças neurodegenerativas. Já em relação à neoplasias, a apolipoproteína têm se demonstrado regulada negativamente em ambientes peritumoral em diversos tipos de câncer, como mama, próstata, ovário, esôfago, fígado e colorretal. Desse modo, há a suspeita desta proteína estar ligada à apoptose celular [93,94].

Na presente pesquisa, a apolipoproteína se mostra estar menos expressa no grupo CCR, estando assim condizente com a literatura.

\section{- Uromodulina}

Esta proteína que é de produção exclusiva dos rins é a mais abundante na urina, tedo funções de transporte de íons, imunomoduladora do trato urinário e impedir a agregação de cristais de cálcio [95].

$\mathrm{Na}$ literatura, a Uromodulina é relacionada à doenças renais, sendo citada por vezes como marcador de doenças renais agudas e crônicas, além de se apresentar como possível biomarcador de neoplasias renais, estando regulado negativamente nesses casos $[96,97]$.

Apesar dessa proteína não ser correlacionada ao CCR na literatura, no presente estudo esta proteína se demonstrou regulada negativamente nas urinas de pacientes CCR.

\section{- Cininogênio 1}


Esta proteína, produzida no fígado, é a mais abundante no plasma e possuí um relevante papel na via intrínseca da cascata de coagulação [98]. O Cininogênio 1 também é descrito como possível biomarcador sérico e tecidual, estando regulado positivamente, para CCR [22,99].

Nesta pesquisa o Cininogênio 1 se encontra diminuído no grupo CCR quando comparado ao controle.

\section{- Beta-2-microglobulina (B2M)}

É uma proteína encontrada na superfície das células nucleares em fluidos corporais, o que o torna um componente do complexo de histocompatibilidade [100]. Sua regulação positiva é relacionada ao risco de desenvolvimento do CCR, o que corrobora com o presente estudo aonde a B2M se encontra aumentada na urina de indivíduos CCR.

\section{- Proteína da matriz extracelular semelhante a fibulina contendo EGF (EFEMP1)}

Participante da família das fibulinas, que estão ligadas a diversos processos biológicos, a EFEMP1, segundo estudos, quando regulada negativamente é associada a tumores avançados de cólon, o que caracteriza pior prognóstico e metástases linfonodais [101,102].

Esta proteína estava em maiores quantidades no grupo controle no presente estudo.

\section{- Alfa-amilase}

Apesar de na literatura não apresentar ligação ao CCR, esta proteína é por vezes citada como marcador de processos inflamatórios e alguns tumores, como mama, pulmão, tireoide, ovário, plasmocitomas pulmonares e mamárias [103,104].

Nesta análise a alfa-amilase estava regulada negativamente no grupo CCR.

\section{- Fragmento de proteína 1 de interação com a fosfatidilinositol-3-quinase}

A via da fosfatidilinositol-3-quinase (PI3K) é intimamente relacionada com a o processo de carcinogênese, inclusive no caso do CCR [105]. Porém no presente estudo foi percebido uma maior concentração dessa proteína no grupo controle.

\section{- Proteína Titina}


Apesar do gene TTN mutado se relacionar por diversas vezes a tumores, ainda não se sabe ao certo papel da titina na carcinogênese [106]. Porém quando alterada, essa proteína é relacionada ao desenvolvimento de desordens neuromusculares e cardiopatias, sendo considerada um possível marcador urinário [107,108].

Nesta pesquisa a titina estava mais presenta nas amostras do grupo controle do que no grupo CCR.

\section{- Domínios de homologia à plecstrina contendo membro 5 da família $\mathrm{A}$}

Uma vez que os domínios de homologia à plecstrina são correlacionados a carcinogênese, por fazer parte da via PI3k/AKT, mutações presentes nesses domínios estão ligadas à certos tumores, como mama, cólon, ovário, pulmão, endométrio e melanomas [109$111]$.

No presente estudo, esta proteína estava regulada negativamente no grupo CCR.

\subsection{Resultados além do PIC}

Os autores deste PIC em colaboração com Bruno A. Alves Martins (Universidade de Brasília, divisão de coloproctologia), Mickaella M. Martins (Universidade de Brasília, graduanda e biologia), Paulo G. de Oliveira (Universidade de Brasília, divisão de coloproctologia) e Aline Maria Araujo Martins (Universidade de Brasília, Instituto de Biologia; Centro Universitário de Brasília, grupo de medicina translacional; CEMBIO - Centro de Metabolómica y Bioanálisis, CEU San Pablo Madrid, Spain) submeteram um artigo de revisão sobre o nome "Biomarkers in colorectal cancer: the role of translational proteomics" (submissão segue em anexo) à revista "Frontiers of Oncology" (A2 em medicina).

Além disso, foi realizada a capacitação dos autores na obtenção de lipídios, tendo em vista que o foco inicial do projeto era da lipidômica. O método utilizado para se obter os lipídios foi o protocolo de Bligh e Dyer, este consistem em nove passos:

1. 150 L de plasma EDTA

2. $190 \mathrm{~L}$ de $\mathrm{CHCl} 3$

3. $375 \mathrm{~L}$ de $\mathrm{MeOH}$

4. Levar amostra ao vórtex por 2 minutos 


\section{5. $167,4 \mathrm{~L}$ de $\mathrm{CHCl} 3$ \\ 6. $150 \mathrm{~L}$ de miliQ}

7. Centrifugar a amostra por 5 minutos a $14000 \mathrm{rpm}$

8. Transferir porção inferior para um novo tubo (fase $\mathrm{CHCl} 3$ )

9. Secar em SpeedVac.

\section{Conclusão}

A análise documental mostrou que 18 proteínas, sendo 13 urinárias e 5 plasmáticas, possuem relevância e podem implicar em possíveis biomarcadores. Porém, o método utilizado nesta pesquisa demonstra uma visão geral da amostra, possuindo baixo valor na aplicabilidade clínica. Assim, deve-se realizar futuras análises marcando essas proteínas relevantes e traçando seu comportamento de forma individualizada nas amostras.

Além disso, a prospecção proteômica como única análise pode ter baixa relevância clínica quando não aliado a outros ramos da metabolômica. Desse modo, se faz necessário a integração dos diversos métodos de análise, com a finalidade de chegar mais próximo de um padrão que correlacione a genômica, transcriptômica e metabolômica. Assim, levantando possíveis biomarcadores com valor diagnóstico, preditivo e prognóstico.

\section{Referências}

1. Siegel RL, Miller KD, Jemal A. Cancer statistics, 2018. CA. Cancer J. Clin. 2018;

2. sus+ MINISTÉRIO DA SAÚDE Agência Brasileira do ISBN [Internet]. [cited 2019 Aug 2]. Available from: https://www.inca.gov.br/sites/ufu.sti.inca.local/files//media/document//estimativaincidencia-de-cancer-no-brasil-2018.pdf

3. Arvelo F, Sojo F, Cotte C. Biology of colorectal cancer. [cited 2018 Jul 30];Available from: www.ecancer.org

4. Fearon ER, Vogelstein B. A genetic model for colorectal tumorigenesis. Cell [Internet]. 1990 Jun 1 [cited 2018 Jul 30];61(5):759-67. Available from: http://www.ncbi.nlm.nih.gov/pubmed/2188735

5. Ang CS, Baker MS, Nice EC. Mass Spectrometry-Based Analysis for the Discovery and Validation of Potential Colorectal Cancer Stool Biomarkers [Internet]. In: Methods in enzymology. 2017 [cited 2018 Jul 30]. p. 247-274.Available from: http://www.ncbi.nlm.nih.gov/pubmed/28137566

6. Rutka M, Bor R, Bálint A, Fábián A, Milassin Á, Nagy F, et al. Diagnostic Accuracy of Five Different Fecal Markers for the Detection of Precancerous and Cancerous Lesions of the Colorectum. Mediators Inflamm. [Internet]. 2016 Jun 16 [cited 2018 Jul 30];2016:1-6. Available from: http://www.hindawi.com/journals/mi/2016/2492081/

7. Oliveira LA De, Roberto P, Pinho A De. Projeto Diretrizes Rastreamento e Vigilância do Câncer Coloretal . Prevenção secundária e detecção precoce . Trial. 2008;2:1-34.

8. Brenner H, Chang-Claude J, Seiler CM, Rickert A, Hoffmeister M. Protection From Colorectal Cancer After Colonoscopy. Ann. Intern. Med. [Internet]. 2011 Jan 4 [cited 2019 May 17];154(1):22. Available 
from: http://www.ncbi.nlm.nih.gov/pubmed/21200035

9. DeSantis CECCE, Lin CCCCCCC, Mariotto AAB, Siegel RRLRRL, Stein KDKKD, Kramer JJL, et al. Cancer treatment and survivorship statistics, 2014. CA. Cancer J. Clin. 2014;

10. Wang K, Huang C, Nice EC. Proteomics, genomics and transcriptomics: their emerging roles in the discovery and validation of colorectal cancer biomarkers. Expert Rev. Proteomics [Internet]. 2014 Apr [cited 2018 Jul 30];11(2):179-205. Available from: http://www.ncbi.nlm.nih.gov/pubmed/24611605

11. Zauber AG, Winawer SJ, O’Brien MJ, Lansdorp-Vogelaar I, van Ballegooijen M, Hankey BF, et al. Colonoscopic Polypectomy and Long-Term Prevention of Colorectal-Cancer Deaths. N. Engl. J. Med. [Internet]. 2012 Feb 23 [cited 2019 May 17];366(8):687-696. Available from: http://www.nejm.org/doi/abs/10.1056/NEJMoa1100370

12. Liang PS, Dominitz JA. Colorectal Cancer Screening. Med. Clin. North Am. [Internet]. 2019 Jan [cited 2019 May 17];103(1):111-123. Available from: https://linkinghub.elsevier.com/retrieve/pii/S0025712518301019

13. Wolf AMD, Fontham ETH, Church TR, Flowers CR, Guerra CE, LaMonte SJ, et al. Colorectal cancer screening for average-risk adults: 2018 guideline update from the American Cancer Society. CA. Cancer J. Clin. [Internet]. 2018 Jul 30 [cited 2018 Jul 30];68(4):250-281. Available from: http://www.ncbi.nlm.nih.gov/pubmed/29846947

14. Bailey JR, Aggarwal A, Imperiale TF. Colorectal Cancer Screening: Stool DNA and Other Noninvasive Modalities. Gut Liver [Internet]. 2016 Mar 23 [cited 2018 Jul 30];10(2):204. Available from: http://www.ncbi.nlm.nih.gov/pubmed/26934885

15. McLachlan S-A, Clements A, Austoker J. Patients' experiences and reported barriers to colonoscopy in the screening context-A systematic review of the literature. Patient Educ. Couns. [Internet]. 2012 Feb [cited 2019 May 17];86(2):137-146. Available from: https://linkinghub.elsevier.com/retrieve/pii/S0738399111001984

16. Navarro M, Nicolas A, Ferrandez A, Lanas A. Colorectal cancer population screening programs worldwide in 2016: An update. World J. Gastroenterol. [Internet]. 2017 [cited 2019 May 17];23(20):3632. Available from: http://www.wjgnet.com/1007-9327/full/v23/i20/3632.htm

17. Kościelniak-Merak B, Radosavljević B, Zając A, Tomasik PJ. Faecal Occult Blood Point-of-Care Tests. J. Gastrointest. Cancer [Internet]. 2018 Dec 20 [cited 2019 May 17];49(4):402-405. Available from: http://link.springer.com/10.1007/s12029-018-0169-1

18. Issa IA, Noureddine M. Colorectal cancer screening: An updated review of the available options. World J. Gastroenterol. [Internet]. 2017 [cited 2019 May 17];23(28):5086. Available from: http://www.wjgnet.com/1007-9327/full/v23/i28/5086.htm

19. Gonzalez-Pons M, Cruz-Correa M. Colorectal Cancer Biomarkers: Where Are We Now? Biomed Res. Int. [Internet]. 2015 [cited 2019 May 17];2015:1-14. Available from: http://www.hindawi.com/journals/bmri/2015/149014/

20. Alnabulsi A, Murray GI. Integrative analysis of the colorectal cancer proteome: potential clinical impact. Expert Rev. Proteomics [Internet]. 2016 Oct 2 [cited 2019 May 17];13(10):917-927. Available from: https://www.tandfonline.com/doi/full/10.1080/14789450.2016.1233062

21. Chauvin A, Boisvert F-M. Clinical Proteomics in Colorectal Cancer, a Promising Tool for Improving Personalised Medicine. Proteomes [Internet]. 2018 Dec 2 [cited 2019 May 17];6(4):49. Available from: http://www.mdpi.com/2227-7382/6/4/49

22. Quesada-Calvo F, Massot C, Bertrand V, Longuespée R, Blétard N, Somja J, et al. OLFM4, KNG1 and Sec24C identified by proteomics and immunohistochemistry as potential markers of early colorectal cancer stages. Clin. Proteomics [Internet]. 2017 Dec 24 [cited 2018 Jul 30];14(1):9. Available from: http://clinicalproteomicsjournal.biomedcentral.com/articles/10.1186/s12014-017-9143-3

23. Ma H, Chen G, Guo M. Mass spectrometry based translational proteomics for biomarker discovery and application in colorectal cancer. PROTEOMICS - Clin. Appl. [Internet]. 2016 Apr [cited 2018 Jul 30];10(4):503-515. Available from: http://www.ncbi.nlm.nih.gov/pubmed/26616366

24. Tariq K, Ghias K. Colorectal cancer carcinogenesis: a review of mechanisms. Cancer Biol. Med. [Internet]. 2016 Mar [cited 2019 Jul 31];13(1):120-35. Available from: http://www.ncbi.nlm.nih.gov/pubmed/27144067

25. Smith G, Carey FA, Beattie J, Wilkie MJ V, Lightfoot TJ, Coxhead J, et al. Mutations in APC, Kirsten- 
ras, and p53--alternative genetic pathways to colorectal cancer. Proc. Natl. Acad. Sci. U. S. A. [Internet]. 2002 Jul 9 [cited 2019 Jul 31];99(14):9433-8. Available from: http://www.ncbi.nlm.nih.gov/pubmed/12093899

26. Weisenberger DJ, Siegmund KD, Campan M, Young J, Long TI, Faasse MA, et al. CpG island methylator phenotype underlies sporadic microsatellite instability and is tightly associated with BRAF mutation in colorectal cancer. Nat. Genet. [Internet]. 2006 Jul 25 [cited 2019 Jul 31];38(7):787-793. Available from: http://www.ncbi.nlm.nih.gov/pubmed/16804544

27. Sameer AS, Nissar S, Fatima K. Mismatch repair pathway. Eur. J. Cancer Prev. [Internet]. 2014 Jul [cited 2019 Jul 31];23(4):246-257. Available from: http://www.ncbi.nlm.nih.gov/pubmed/24614649

28. Weiser MR. AJCC 8th Edition: Colorectal Cancer. Ann. Surg. Oncol. [Internet]. 2018 Jun 3 [cited 2019 May 17];25(6):1454-1455. Available from: http://link.springer.com/10.1245/s10434-018-6462-1

29. de Wit M, Fijneman RJA, Verheul HMW, Meijer GA, Jimenez CR. Proteomics in colorectal cancer translational research: Biomarker discovery for clinical applications. Clin. Biochem. [Internet]. 2013 Apr [cited 2019 May 17];46(6):466-479. Available from: https://linkinghub.elsevier.com/retrieve/pii/S0009912012006236

30. Coghlin C, Murray GI. Biomarkers of colorectal cancer: Recent advances and future challenges. PROTEOMICS - Clin. Appl. [Internet]. 2015 Feb [cited 2018 Jul 30];9(1-2):64-71. Available from: http://www.ncbi.nlm.nih.gov/pubmed/25311658

31. Alvarez-Chaver P, Otero-Estévez O, Páez de la Cadena M, Rodríguez-Berrocal FJ, MartínezZorzano VS. Proteomics for discovery of candidate colorectal cancer biomarkers. World J. Gastroenterol. [Internet]. 2014 Apr 14 [cited 2019 May 17];20(14):3804-24. Available from: http://www.ncbi.nlm.nih.gov/pubmed/24744574

32. Bhalla A, Zulfiqar M, Bluth MH. Molecular Diagnostics in Colorectal Carcinoma. Clin. Lab. Med. [Internet]. 2018 Jun [cited 2019 May 17];38(2):311-342. Available from: https://linkinghub.elsevier.com/retrieve/pii/S0272271218300088

33. Alnabulsi A, Murray GI. Proteomics for early detection of colorectal cancer: recent updates. Expert Rev. Proteomics [Internet]. 2018 Jan 2 [cited 2019 May 29];15(1):55-63. Available from: https://www.tandfonline.com/doi/full/10.1080/14789450.2018.1396893

34. Alexander F, Weller D. Evaluation of the UK Colorectal Cancer Screening Pilot Final Report The UK CRC Screening Pilot Evaluation Team [Internet]. [cited 2019 May 17]. Available from: https://www.sehd.scot.nhs.uk/publications/ColorectalCaScreenPilotEval2003.pdf

35. Logan RFA, Patnick J, Nickerson C, Coleman L, Rutter MD, von Wagner C. Outcomes of the Bowel Cancer Screening Programme (BCSP) in England after the first 1 million tests. Gut [Internet]. 2012 Oct [cited 2019 May 17];61(10):1439-1446. Available from: http:/gut.bmj.com/lookup/doi/10.1136/gutjnl2011-300843

36. Plumb AA, Ghanouni A, Rainbow S, Djedovic N, Marshall S, Stein J, et al. Patient factors associated with non-attendance at colonoscopy after a positive screening faecal occult blood test. J. Med. Screen. [Internet]. 2017 Mar 8 [cited 2019 May 17];24(1):12-19. Available from: http://journals.sagepub.com/doi/10.1177/0969141316645629

37. Ghazanfar S, Fatima I, Aslam M, Musharraf SG, Sherman NE, Moskaluk C, et al. Identification of actin beta-like 2 (ACTBL2) as novel, upregulated protein in colorectal cancer. J. Proteomics [Internet]. 2017 Jan [cited 2019 May 17];152:33-40. Available from: https://linkinghub.elsevier.com/retrieve/pii/S1874391916304493

38. Hao J-J, Zhi X, Wang Y, Zhang Z, Hao Z, Ye R, et al. Comprehensive Proteomic Characterization of the Human Colorectal Carcinoma Reveals Signature Proteins and Perturbed Pathways. Sci. Rep. [Internet]. 2017 Mar 9 [cited 2019 May 17];7(1):42436. Available from: http://www.nature.com/articles/srep42436

39. Yamamoto T, Kudo M, Peng W-X, Takata H, Takakura H, Teduka K, et al. Identification of aldolase A as a potential diagnostic biomarker for colorectal cancer based on proteomic analysis using formalinfixed paraffin-embedded tissue. Tumor Biol. [Internet]. 2016 Oct 28 [cited 2019 May 17];37(10):13595-13606. Available from: http://link.springer.com/10.1007/s13277-016-5275-8

40. Ganepola GA. Use of blood-based biomarkers for early diagnosis and surveillance of colorectal cancer. World J. Gastrointest. Oncol. [Internet]. 2014 [cited 2019 May 17];6(4):83. Available from: http://www.wjgnet.com/1948-5204/full/v6/i4/83.htm 
41. Fan N-J, Chen H-M, Song W, Zhang Z-Y, Zhang M-D, Feng L-Y, et al. Macrophage mannose receptor 1 and S100A9 were identified as serum diagnostic biomarkers for colorectal cancer through a label-free quantitative proteomic analysis. Cancer Biomarkers [Internet]. 2016 Feb 23 [cited 2019 May 17];16(2):235-243. Available from:

http://www.medra.org/servlet/aliasResolver?alias=iospress\&doi=10.3233/CBM-150560

42. Peltier J, Roperch J-P, Audebert S, Borg J-P, Camoin L. Quantitative proteomic analysis exploring progression of colorectal cancer: Modulation of the serpin family. J. Proteomics [Internet]. 2016 Oct [cited 2019 May 17];148:139-148. Available from: https://linkinghub.elsevier.com/retrieve/pii/S1874391916303426

43. Yu J, Zhai X, Li X, Zhong C, Guo C, Yang F, et al. Identification of MST1 as a potential early detection biomarker for colorectal cancer through a proteomic approach. Sci. Rep. [Internet]. 2017 Dec 27 [cited 2019 May 17];7(1):14265. Available from: http://www.nature.com/articles/s41598-017-14539-x

44. Wang J, Mouradov D, Wang X, Jorissen RN, Chambers MC, Zimmerman LJ, et al. Colorectal Cancer Cell Line Proteomes Are Representative of Primary Tumors and Predict Drug Sensitivity. Gastroenterology [Internet]. 2017 [cited 2019 May 17];153(4):1082-1095. Available from: http://www.ncbi.nlm.nih.gov/pubmed/28625833

45. Guo J, Zhu C, Yang K, Li J, Du N, Zong M, et al. Poly(C)-binding protein 1 mediates drug resistance in colorectal cancer. Oncotarget [Internet]. 2017 Feb 21 [cited 2019 May 17];8(8):13312-13319. Available from: http://www.ncbi.nlm.nih.gov/pubmed/28076324

46. Martin P, Noonan S, Mullen MP, Scaife C, Tosetto M, Nolan B, et al. Predicting response to vascular endothelial growth factor inhibitor and chemotherapy in metastatic colorectal cancer. BMC Cancer [Internet]. 2014 Dec 27 [cited 2019 May 17];14(1):887. Available from: http://bmccancer.biomedcentral.com/articles/10.1186/1471-2407-14-887

47. Benson AB, Venook AP, Al-Hawary MM, Cederquist L, Chen Y-J, Ciombor KK, et al. NCCN Guidelines Insights: Colon Cancer, Version 2.2018. J. Natl. Compr. Cancer Netw. [Internet]. 2018 Apr 9 [cited 2019 May 17];16(4):359-369. Available from: http://www.ncbi.nlm.nih.gov/pubmed/29632055

48. Habr-Gama A, Perez RO, Nadalin W, Sabbaga J, Ribeiro U, Silva e Sousa AH, et al. Operative Versus Nonoperative Treatment for Stage 0 Distal Rectal Cancer Following Chemoradiation Therapy. Trans. ... Meet. Am. Surg. Assoc. [Internet]. 2004 [cited 2018 Nov 7];CXXII(NA;):309-316. Available from: https://insights.ovid.com/crossref?an=00153307-200401220-00032

49. Chauvin A, Wang C-S, Geha S, Garde-Granger P, Mathieu A-A, Lacasse V, et al. The response to neoadjuvant chemoradiotherapy with 5-fluorouracil in locally advanced rectal cancer patients: a predictive proteomic signature. Clin. Proteomics [Internet]. 2018 Dec 13 [cited 2018 Nov 7];15(1):16. Available from: https://clinicalproteomicsjournal.biomedcentral.com/articles/10.1186/s12014-0189192-2

50. Ong MLH, Schofield JB. Assessment of lymph node involvement in colorectal cancer. World J. Gastrointest. Surg. [Internet]. 2016 Mar 27 [cited 2019 May 17];8(3):179-92. Available from: http://www.ncbi.nlm.nih.gov/pubmed/27022445

51. Low G, Tho LM, Leen E, Wiebe E, Kakumanu S, McDonald AC, et al. The role of imaging in the pre-operative staging and post-operative follow-up of rectal cancer. Surgeon [Internet]. 2008 Aug [cited 2019 May 17];6(4):222-31. Available from: http://www.ncbi.nlm.nih.gov/pubmed/18697365

52. Das V, Kalita J, Pal M. Predictive and prognostic biomarkers in colorectal cancer: A systematic review of recent advances and challenges. Biomed. Pharmacother. [Internet]. 2017 Mar [cited 2018 Nov 8];87:8-19. Available from: http://www.ncbi.nlm.nih.gov/pubmed/28040600

53. Oldenhuis CNAM, Oosting SF, Gietema JA, de Vries EGE. Prognostic versus predictive value of biomarkers in oncology. Eur. J. Cancer [Internet]. 2008 May [cited 2019 May 17];44(7):946-953. Available from: https://linkinghub.elsevier.com/retrieve/pii/S0959804908002335

54. O'Connell JB, Maggard MA, Ko CY. Colon Cancer Survival Rates With the New American Joint Committee on Cancer Sixth Edition Staging. JNCI J. Natl. Cancer Inst. [Internet]. 2004 Oct 6 [cited 2019 May 17];96(19):1420-1425. Available from: http://www.ncbi.nlm.nih.gov/pubmed/15467030

55. Hugen N, van de Velde CJH, de Wilt JHW, Nagtegaal ID. Metastatic pattern in colorectal cancer is strongly influenced by histological subtype. Ann. Oncol. [Internet]. 2014 Mar 1 [cited 2019 May 17];25(3):651-657. Available from: https://academic.oup.com/annonc/articlelookup/doi/10.1093/annonc/mdt591 
56. Zhu D, Zhong Y, Wu H, Ye L, Wang J, Li Y, et al. Predicting metachronous liver metastasis from colorectal cancer using serum proteomic fingerprinting. J. Surg. Res. [Internet]. 2013 Oct [cited 2019 May 17];184(2):861-866. Available from: https://linkinghub.elsevier.com/retrieve/pii/S002248041300437X

57. van Huizen NA, Coebergh van den Braak RRJ, Doukas M, Dekker LJM, IJzermans JNM, Luider TM. Up-regulation of collagen proteins in colorectal liver metastasis compared with normal liver tissue. J. Biol. Chem. [Internet]. 2019 Jan 4 [cited 2019 May 17];294(1):281-289. Available from: http://www.jbc.org/lookup/doi/10.1074/jbc.RA118.005087

58. Lalmahomed Z, Broker M, Roest H, Van Huizen N, Dekker L, Calame W, et al. P-0284 * COLLAGEN PEPTIDES IN URINE: A NEW PROMISING BIOMARKER FOR THE DETECTION OF COLORECTAL LIVER METASTASES. Ann. Oncol. [Internet]. 2013 Jun 1 [cited 2019 May 17];24(suppl 4):iv116-iv116. Available from: https://academic.oup.com/annonc/articlelookup/doi/10.1093/annonc/mdt203.282

59. Lalmahomed ZS, Bröker ME, van Huizen NA, Coebergh van den Braak RRJ, Dekker LJ, Rizopoulos D, et al. Hydroxylated collagen peptide in urine as biomarker for detecting colorectal liver metastases. Am. J. Cancer Res. [Internet]. 2016 [cited 2019 May 17];6(2):321-30. Available from: http://www.ncbi.nlm.nih.gov/pubmed/27186406

60. Clarke CN, Lee MS, Wei W, Manyam G, Jiang ZQ, Lu Y, et al. Proteomic Features of Colorectal Cancer Identify Tumor Subtypes Independent of Oncogenic Mutations and Independently Predict Relapse-Free Survival. Ann. Surg. Oncol. 2017;

61. Cantú MD, Carrilho E, Wulff NA, Palma MS. Seqüenciamento de peptídeos usando espectrometria de massas: um guia prático. Quim. Nova [Internet]. 2008 [cited 2019 Aug 2];31(3):669-675. Available from: http://www.scielo.br/scielo.php?script=sci_arttext\&pid=S010040422008000300034\&lng=pt\&nrm=iso\&tlng=pt

62. Matthiesen R, Bunkenborg J. Introduction to Mass Spectrometry-Based Proteomics [Internet]. 2013 [cited 2019 Aug 2]. p. 1-45.Available from: http://link.springer.com/10.1007/978-1-62703-392-3_1

63. Ciocan-Cartita CA, Jurj A, Buse M, Gulei D, Braicu C, Raduly L, et al. The Relevance of Mass Spectrometry Analysis for Personalized Medicine through Its Successful Application in Cancer “Omics.” Int. J. Mol. Sci. [Internet]. 2019 May 25 [cited 2019 Aug 2];20(10):2576. Available from: https://www.mdpi.com/1422-0067/20/10/2576

64. Witten DM, Tibshirani R. A comparison of fold-change and the t-statistic for microarray data analysis [Internet]. 2007 [cited 2019 Aug 2]. Available from: http://statweb.stanford.edu/ tibs/ftp/FCTComparison.pdf

65. Choi J-W, Liu H, Shin DH, Yu GI, Hwang JS, Kim ES, et al. Proteomic and cytokine plasma biomarkers for predicting progression from colorectal adenoma to carcinoma in human patients. Proteomics [Internet]. 2013 Aug [cited 2019 Aug 4];13(15):2361-2374. Available from: http://doi.wiley.com/10.1002/pmic.201200550

66. Woong-Shick A, Sung-Pil P, Su-Mi B, Joon-Mo L, Sung-Eun N, Gye-Hyun N, et al. Identification of hemoglobin-alpha and -beta subunits as potential serum biomarkers for the diagnosis and prognosis of ovarian cancer. Cancer Sci. [Internet]. 2005 Mar [cited 2019 Aug 4];96(3):197-201. Available from: http://doi.wiley.com/10.1111/j.1349-7006.2005.00029.x

67. Rho J, Qin S, Wang JY, Roehrl MHA. Proteomic Expression Analysis of Surgical Human Colorectal Cancer Tissues: Up-Regulation of PSB7, PRDX1, and SRP9 and Hypoxic Adaptation in Cancer. J. Proteome Res. [Internet]. 2008 Jul [cited 2019 Aug 4];7(7):2959-2972. Available from: http://pubs.acs.org/doi/abs/10.1021/pr8000892

68. Ang C-S, Rothacker J, Patsiouras H, Burgess AW, Nice EC. Murine fecal proteomics: A model system for the detection of potential biomarkers for colorectal cancer. J. Chromatogr. A [Internet]. 2010 May [cited 2019 Aug 4];1217(19):3330-3340. Available from: https://linkinghub.elsevier.com/retrieve/pii/S0021967309014824

69. Jass JR, Baker K, Zlobec I, Higuchi T, Barker M, Buchanan D, et al. Advanced colorectal polyps with the molecular and morphological features of serrated polyps and adenomas: concept of a "fusion" pathway to colorectal cancer. Histopathology [Internet]. 2006 Aug [cited 2019 Aug 4];49(2):121-131. Available from: http://www.ncbi.nlm.nih.gov/pubmed/16879389

70. Jass JR, Biden KG, Cummings MC, Simms LA, Walsh M, Schoch E, et al. Characterisation of a subtype 
of colorectal cancer combining features of the suppressor and mild mutator pathways. J. Clin. Pathol. [Internet]. 1999 Jun [cited 2019 Aug 4];52(6):455-60. Available from: http://www.ncbi.nlm.nih.gov/pubmed/10562815

71. Kudo S, Kashida H, Tamura S, Nakajima T. The problem of \&quot;flat\&quot; colonic adenoma. Gastrointest. Endosc. Clin. N. Am. [Internet]. 1997 Jan [cited 2019 Aug 4];7(1):87-98. Available from: http://www.ncbi.nlm.nih.gov/pubmed/8995115

72. Kudo S-E, Sugihara Y, Kida H, Ishida F, Miyachi H, Mori Y, et al. Depressed-Type Colonic Lesions and \&quot;De Novo\&quot; Cancer in Familial Adenomatous Polyposis: A Colonoscopist's Viewpoint. ISRN Gastroenterol. [Internet]. 2013 Feb 27 [cited 2019 Aug 4];2013:838134. Available from: http://www.ncbi.nlm.nih.gov/pubmed/23533795

73. KIDA H, TAKANO Y, YAMAMOTO K, MORI M, YANAGA K, TANAKA J-I, et al. A single nucleotide polymorphism in fibronectin 1 determines tumor shape in colorectal cancer. Oncol. Rep. [Internet]. 2014 Aug [cited 2019 Aug 4];32(2):548-552. Available from: https://www.spandidos-publications.com/10.3892/or.2014.3251

74. Cai X, Liu C, Zhang T-N, Zhu Y-W, Dong X, Xue P. Down-regulation of FN1 inhibits colorectal carcinogenesis by suppressing proliferation, migration, and invasion. J. Cell. Biochem. [Internet]. 2018 Jun [cited 2019 Aug 4];119(6):4717-4728. Available from: http://doi.wiley.com/10.1002/jcb.26651

75. Kunapuli SP, Singh H, Singh P, Kumar A. Ceruloplasmin gene expression in human cancer cells. Life Sci. [Internet]. 1987 Jun [cited 2019 Aug 4];40(23):2225-2228. Available from: https://linkinghub.elsevier.com/retrieve/pii/0024320587900579

76. Balmaña M, Sarrats A, Llop E, Barrabés S, Saldova R, Ferri MJ, et al. Identification of potential pancreatic cancer serum markers: Increased sialyl-Lewis X on ceruloplasmin. Clin. Chim. Acta [Internet]. 2015 Mar 10 [cited 2019 Aug 4];442:56-62. Available from: http://www.ncbi.nlm.nih.gov/pubmed/25595436

77. Nayak SB, Bhat VR, Mayya SS. Serum copper, ceruloplasmin and thiobarbituric acid reactive substance status in patients with ovarian cancer. Indian J. Physiol. Pharmacol. [Internet]. 2004 Oct [cited 2019 Aug 4];48(4):486-8. Available from: http://www.ncbi.nlm.nih.gov/pubmed/15907060

78. Han IW, Jang J-Y, Kwon W, Park T, Kim Y, Lee KB, et al. Ceruloplasmin as a prognostic marker in patients with bile duct cancer. Oncotarget [Internet]. 2017 Apr 25 [cited 2019 Aug 4];8(17):2902829037. Available from: http://www.ncbi.nlm.nih.gov/pubmed/28423673

79. Huang X. Iron overload and its association with cancer risk in humans: evidence for iron as a carcinogenic metal. Mutat. Res. Mol. Mech. Mutagen. [Internet]. 2003 Dec 10 [cited 2019 Aug 4];533(1-2):153-171. Available from: http://www.ncbi.nlm.nih.gov/pubmed/14643418

80. ELLIOTT RL, ELLIOTT MC, WANG F, HEAD JF. Breast Carcinoma and the Role of Iron Metabolism. Ann. N. Y. Acad. Sci. [Internet]. 1993 Nov 30 [cited 2019 Aug 4];698(1 Breast Cancer):159-166. Available from: http://www.ncbi.nlm.nih.gov/pubmed/8279755

81. Brookes MJ, Hughes S, Turner FE, Reynolds G, Sharma N, Ismail T, et al. Modulation of iron transport proteins in human colorectal carcinogenesis. Gut [Internet]. 2006 Oct [cited 2019 Aug 4];55(10):1449- 60. Available from: http://www.ncbi.nlm.nih.gov/pubmed/16641131

82. Mainous AG, Gill JM, Everett CJ, Everett CJ. Transferrin saturation, dietary iron intake, and risk of cancer. Ann. Fam. Med. [Internet]. 2005 [cited 2019 Aug 4];3(2):131-7. Available from: http://www.ncbi.nlm.nih.gov/pubmed/15798039

83. Ward DG, Suggett N, Cheng Y, Wei W, Johnson H, Billingham LJ, et al. Identification of serum biomarkers for colon cancer by proteomic analysis. Br. J. Cancer [Internet]. 2006 Jun 6 [cited 2019 Aug 4];94(12):1898-1905. Available from: http://www.nature.com/articles/6603188

84. Altobelli E, Angeletti PM, Latella G. Role of Urinary Biomarkers in the Diagnosis of Adenoma and Colorectal Cancer: A Systematic Review and Meta-Analysis. J. Cancer [Internet]. 2016 [cited 2019 May 29];7(14):1984-2004. Available from: http://www.jcancer.org/v07p1984.htm

85. Colbert Maresso K, Vilar E, Hawk ET. Urinary PGE-M in colorectal cancer: predicting more than risk? Cancer Prev. Res. (Phila). [Internet]. 2014 Oct [cited 2019 May 29];7(10):969-72. Available from: http://www.ncbi.nlm.nih.gov/pubmed/25070664

86. Bezawada N, Song M, Wu K, Mehta RS, Milne GL, Ogino S, et al. Urinary PGE-M levels are associated with risk of colorectal adenomas and chemopreventive response to anti-inflammatory drugs. 
Cancer Prev. Res. 2014;7(7):758-765.

87. Johnson JC, Schmidt CR, Shrubsole MJ, Billheimer DD, Joshi PR, Morrow JD, et al. Urine PGE-M: A Metabolite of Prostaglandin E2 as a Potential Biomarker of Advanced Colorectal Neoplasia. Clin. Gastroenterol. Hepatol. [Internet]. 2006 Nov [cited 2019 May 29];4(11):1358-1365. Available from: http://www.ncbi.nlm.nih.gov/pubmed/16996805

88. Shrubsole MJ, Cai Q, Wen W, Milne G, Smalley WE, Chen Z, et al. Urinary Prostaglandin E2 Metabolite and Risk for Colorectal Adenoma. Cancer Prev. Res. [Internet]. 2012 Feb 1 [cited 2019 May 29];5(2):336-342. Available from: http://www.ncbi.nlm.nih.gov/pubmed/22166248

89. Kehlet SN, Sanz-Pamplona R, Brix S, Leeming DJ, Karsdal MA, Moreno V. Excessive collagen turnover products are released during colorectal cancer progression and elevated in serum from metastatic colorectal cancer patients. Sci. Rep. [Internet]. 2016 Nov 28 [cited 2019 Aug 5];6(1):30599. Available from: http://www.ncbi.nlm.nih.gov/pubmed/27465284

90. Zou X, Feng B, Dong T, Yan G, Tan B, Shen H, et al. Up-regulation of type I collagen during tumorigenesis of colorectal cancer revealed by quantitative proteomic analysis. J. Proteomics [Internet]. 2013 Dec [cited 2019 Aug 6];94:473-485. Available from: https://linkinghub.elsevier.com/retrieve/pii/S1874391913005356

91. Yu Y, Liu D, Liu Z, Li S, Ge Y, Sun W, et al. The inhibitory effects of COL1A2 on colorectal cancer cell proliferation, migration, and invasion. J. Cancer [Internet]. 2018 [cited 2019 Aug 5];9(16):2953-2962. Available from: http://www.jcancer.org/v09p2953.htm

92. Bröker MEE, Lalmahomed ZS, Roest HP, van Huizen NA, Dekker LJM, Calame W, et al. Collagen Peptides in Urine: A New Promising Biomarker for the Detection of Colorectal Liver Metastases. PLoS One [Internet]. 2013 Aug 16 [cited 2019 Aug 5];8(8):e70918. Available from: http://www.ncbi.nlm.nih.gov/pubmed/23976965

93. Rassart E, Bedirian A, Do Carmo S, Guinard O, Sirois J, Terrisse L, et al. Apolipoprotein D. Biochim. Biophys. Acta [Internet]. 2000 Oct 18 [cited 2019 Aug 5];1482(1-2):185-98. Available from: http://www.ncbi.nlm.nih.gov/pubmed/11058760

94. Bajo-Grañeras R, Crespo-Sanjuan J, García-Centeno RM, Garrote-Adrados JA, Gutierrez G, GarcíaTejeiro M, et al. Expression and potential role of apolipoprotein D on the death-survival balance of human colorectal cancer cells under oxidative stress conditions. Int. J. Colorectal Dis. [Internet]. 2013 Jun 8 [cited 2019 Aug 5];28(6):751-766. Available from: http://www.ncbi.nlm.nih.gov/pubmed/23296401

95. Botelho TEF, Pereira AK, Teixeira PG, Lage EM, Osanan GC, Silva ACS e. Uromodulin: a new biomarker of fetal renal function? J. Bras. Nefrol. [Internet]. 2016 Dec [cited 2019 Aug 5];38(4):427434. Available from: http://www.ncbi.nlm.nih.gov/pubmed/28001177

96. Trevisani F, Larcher A, Cinque A, Capitanio U, Ripa F, Vago R, et al. The Association of Uromodulin Genotype with Renal Cancer Aggressiveness. Eur. Urol. Focus [Internet]. $2019 \mathrm{Mar}$ [cited 2019 Aug 5];5(2):262-265. Available from: http://www.ncbi.nlm.nih.gov/pubmed/28753889

97. Sandim V, Pereira D de A, Kalume DE, Oliveira-Carvalho AL, Ornellas AA, Soares MR, et al. Proteomic analysis reveals differentially secreted proteins in the urine from patients with clear cell renal cell carcinoma. Urol. Oncol. Semin. Orig. Investig. [Internet]. 2016 Jan [cited 2019 Aug 5];34(1):5.e115.e25. Available from: http://www.ncbi.nlm.nih.gov/pubmed/26420021

98. Wong MKS. Kininogen. Handb. Horm. [Internet]. 2016 Jan 1 [cited 2019 Aug 5];268-e30A-3. Available from: https://www.sciencedirect.com/science/article/pii/B978012801028000180X

99. Yu J, Huang Y, Lin C, Li X, Fang X, Zhong C, et al. Identification of Kininogen 1 as a Serum Protein Marker of Colorectal Adenoma in Patients with a Family History of Colorectal Cancer. J. Cancer [Internet]. 2018 [cited 2019 Aug 5];9(3):540-547. Available from: http://www.ncbi.nlm.nih.gov/pubmed/29535795

100. Li L, Dong M, Wang X-G. The Implication and Significance of Beta 2 Microglobulin. Chin. Med. J. (Engl). [Internet]. $2016 \mathrm{Feb} 20$ [cited 2019 Aug 5];129(4):448-455. Available from: http://www.ncbi.nlm.nih.gov/pubmed/26879019

101. Simsek O, Kocael A, Kemik A, Vatankulu B, Kocael P, Halac M, et al. Decreased preoperative serum fibulin-3 levels in colon cancer patients. Eur. Rev. Med. Pharmacol. Sci. [Internet]. 2015 Nov [cited 2019 Aug 5];19(21):4076-80. Available from: http://www.ncbi.nlm.nih.gov/pubmed/26592829 
102. Tong JD, Jiao NL, Wang YX, Zhang YW, Han F. Downregulation of fibulin-3 gene by promoter methylation in colorectal cancer predicts adverse prognosis. Neoplasma [Internet]. 2011 [cited 2019 Aug 5];58(5):441-8. Available from: http://www.ncbi.nlm.nih.gov/pubmed/21744999

103. Fedrowitz M, Hass R, Bertram C, Löscher W. Salivary $\alpha$-amylase exhibits antiproliferative effects in primary cell cultures of rat mammary epithelial cells and human breast cancer cells. J. Exp. Clin. Cancer Res. [Internet]. 2011 Dec 25 [cited 2019 Aug 5];30(1):102. Available from: http://www.ncbi.nlm.nih.gov/pubmed/22027017

104. Jain S, Roy S, Amin M, Acquafondata M, Yin M, LaFramboise W, et al. Amylase $\alpha-1$ A (AMY1A). Am. J. Surg. Pathol. [Internet]. 2013 Dec [cited 2019 Aug 5];37(12):1824-1830. Available from: http://www.ncbi.nlm.nih.gov/pubmed/24225843

105. Chen J-S, Huang J-Q, Luo B, Dong S-H, Wang R-C, Jiang Z, et al. PIK3CD induces cell growth and invasion by activating AKT/GSK-3 $\beta / \beta$-catenin signaling in colorectal cancer. Cancer Sci. [Internet]. 2019 Mar [cited 2019 Aug 5];110(3):997-1011. Available from: http://www.ncbi.nlm.nih.gov/pubmed/30618098

106. Jia Q, Wang J, He N, He J, Zhu B. Titin mutation associated with responsiveness to checkpoint blockades in solid tumors. JCI Insight [Internet]. 2019 May 16 [cited 2019 Aug 5];4(10). Available from: http://www.ncbi.nlm.nih.gov/pubmed/31092729

107. Misaka T, Yoshihisa A, Takeishi Y. Titin in muscular dystrophy and cardiomyopathy: Urinary titin as a novel marker. Clin. Chim. Acta [Internet]. 2019 Aug 1 [cited 2019 Aug 5];495:123-128. Available from: https://www.sciencedirect.com/science/article/pii/S0009898119317462

108. Matsuo M, Awano H, Maruyama N, Nishio H. Titin fragment in urine: A noninvasive biomarker of muscle degradation [Internet]. In: Advances in clinical chemistry. 2019 [cited 2019 Aug 5]. p. 123.Available from: http://www.ncbi.nlm.nih.gov/pubmed/31122607

109. Shoji K, Oda K, Nakagawa S, Hosokawa S, Nagae G, Uehara Y, et al. The oncogenic mutation in the pleckstrin homology domain of AKT1 in endometrial carcinomas. Br. J. Cancer [Internet]. 2009 Jul 2 [cited 2019 Aug 5];101(1):145-148. Available from: http://www.ncbi.nlm.nih.gov/pubmed/19491896

110. Carpten JD, Faber AL, Horn C, Donoho GP, Briggs SL, Robbins CM, et al. A transforming mutation in the pleckstrin homology domain of AKT1 in cancer. Nature [Internet]. 2007 Jul 4 [cited 2019 Aug 5];448(7152):439-444. Available from: http://www.ncbi.nlm.nih.gov/pubmed/17611497

111. Avila CM, Romeiro NC. Protein tyrosine kinases: challenges in the development of drugs aimed at cancer therapy. Rev. Virtual Química [Internet]. 2010 [cited 2019 Aug 6];2(1). Available from: http://www.gnresearch.org/doi/10.5935/1984-6835.20100007 


\section{ANEXO I- Submissão do artigo}

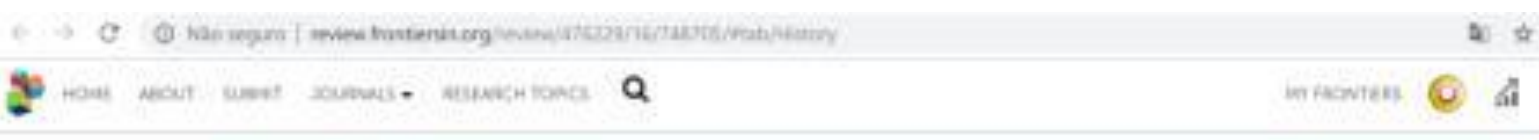

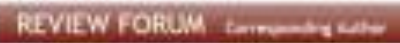

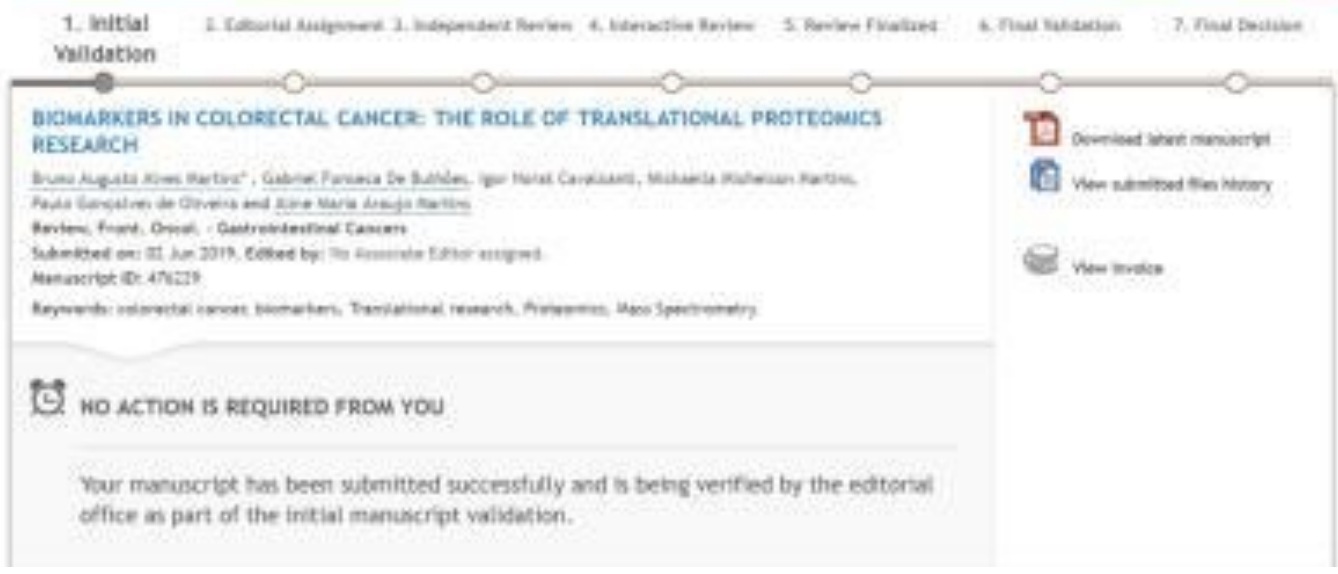

